\title{
Towards Fish Lipid Nutrigenomics: Current State and Prospects for Fin-fish Aquaculture
}

\author{
MICHAEL J. LEAVER ${ }^{1 *}$, JOSÉ M. BAUTISTA ${ }^{2}$, BJÖRN THRANDUR \\ BJÖRNSSON $^{3}$, ELISABETH JÖNSSON ${ }^{3}$, GRIGORIOS KREY ${ }^{4}$, DOUGLAS R. \\ TOCHER $^{1}$, BENTE E. TORSTENSEN ${ }^{5}$ \\ 1. Institute of Aquaculture, University of Stirling, Stirling FK9 4LA, United \\ Kingdom \\ 2. Biochemistry and Molecular Biology IV, Facultad de Veterinaria, Universidad \\ Complutense de Madrid, 28040 Madrid, Spain \\ 3. Fish Endocrinology Laboratory, Department of Zoology and Ecophysiology, \\ Goteborg University, Box 463, S40530 Göteborg, Sweden
4. National Agricultural Research Foundation, Fisheries Research Institute, Nea Peramos, 64007 Kavala, Greece

5. National Institute of Nutrition and Seafood Research, PO Box 2029, Nordnes, 5817 Bergen, Norway

\section{*Corresponding author}

\begin{abstract}
Lipids are the predominant source of energy for fish. The mechanisms by which fish allocate energy from lipids, for metabolism, development, growth and reproduction are critical for understanding key life history strategies and transitions. Currently, the major lipid component in aquaculture diets is fish oil (FO), derived from wild capture fisheries that are exploited at their maximum sustainable limit. The increasing demand from aquaculture for FO will soon exceed supply and threaten the viability of aquaculture. Thus, it is essential to minimize FO use in aquaculture diets. This might be achieved by a greater understanding of lipid storage and muscle growth, or the identification of alternatives to FO in feeds. This review focuses on recent research applying molecular and genomic techniques to the study of fin-fish lipid metabolism from an aquaculture perspective. Accordingly, particular emphasis will be given to fatty acid metabolism and to highly unsaturated fatty acid (HUFA) biosynthesis, and to the transcriptional mechanisms and endocrine factors that regulate these processes in fish. Comparative studies of gene function and distribution are described which, when integrated with recent fish genome sequence information, provide insights into lipid homeostasis and the outcomes associated with the replacement of FO in fish diets.
\end{abstract}

Keywords fatty acid, sea bream, Atlantic salmon, desaturase, elongase, metabolism, PPARs, ghrelin, endocrinology.

\section{INTRODUCTION}


The noun lipid refers to a large and heterogeneous group of substances classified together on the basis of their high solubility in non-polar solvents or their relatedness to such compounds. The vast majority of lipids in eukaryotes are derived from acetyl-CoA and belong to three major classes: straight chain fatty acids, branched, cyclic and other specialised fatty acids, and polyprenoid compounds including carotenoids and sterols and their derivatives. Lipids have a number of major roles in all organisms. Perhaps most importantly they are structural components of cell membranes and they are essential for energy provision and storage. Lipids and fatty acids, along with proteins, are the major macronutrients for fish (Sargent et al. 2002). Fish seem not to have evolved efficient carbohydrate utilization systems in contrast to terrestrial vertebrates where carbohydrates, originating from plant-derived foodstuffs, are major components of the diet of many organisms. Thus, carbohydrates are quantitatively of little importance as nutrients for most fish, suggesting that fish may satisfy structural carbohydrate and storage carbohydrate (glycogen) requirements principally by catabolising amino acids (Cowey and Walton, 1989). Fish are also the most diverse and numerous members of the vertebrates and have a correspondingly diverse array of life history strategies. The mechanisms by which fish allocate energy, from lipids and protein, to development, growth and reproduction are of critical importance in understanding these life history strategies.Ultimately a greater understanding of these mechanisms will guide sustainable fisheries and aquaculture activities.

The growth in fin-fish aquaculture has been made possible by the development of artificial diets or feeds formulated to satisfy essential requirements (amino acids, fatty acids, vitamins and minerals etc), and provide macronutrients (protein, lipid, carbohydrate) and energy in balance to optimise growth. Thus, it has been the requirements of aquaculture that have driven research into fish nutrition including lipid and fatty acid metabolism and its regulation. Dietary lipid and fatty acids can have three primary fates in fish. They can be incorporated into cell membranes and hence the flesh of the fish, they can be oxidised to provide energy, or lipid can be deposited in adipose or other tissues as energy storage (Tocher, 2003). Therefore, from an aquaculture perspective, the lipid (fat) content and the fatty acid composition of the diet must be optimised to enable high growth rates, ensure fish health and, at the same time, maintain the nutritional benefits of fish for the human consumer (Sargent et al. 2002; Tocher, 2003).

The lipid content of pelleted diets has increased greatly in recent years due in part to the technical advancements in the production of feed. This increase is driven by the observation that the more energy that can be supplied by dietary lipid, the less protein will be used for energy and so more dietary protein can be "spared" for synthesis of new tissue/flesh (Hemre and Sandnes, 1999). However, although protein sparing by dietary lipid is widely accepted, the limits to its effectiveness, or the mechanisms by which it might occur, have not been accurately defined for any fish (see Company et al. 1999). Consequently, dietary formulations have maximised lipid content in order to satisfy commercial pressure to increase growth rates and reduce production times, despite the fact that there is a strong relationship between dietary lipid levels and undesirable levels of lipid in the carcass of fish (Cowey and Cho, 1993).

The specific fatty acid composition of fish diets, and indeed human diets, is also of critical importance. Fish have a varying requirement, depending on the species, for n-3 
or $\omega 3$ long-chain polyunsaturated fatty acids (PUFA), eicosapentaenoic acid (EPA; 20:5n-3) and docosahexaenoic acid (DHA; 22:6n-3), sometimes referred to as n-3 HUFA (highly unsaturated fatty acids; Henderson and Sargent, 1984). Humans have a limited capacity to synthesise n-3 HUFA from shorter chain precursors, and fish have become vitally important as the only significant source of n-3 HUFA, particularly in the Western foodbasket. Fish oil, rich in n-3 HUFA and derived from industrial fisheries, e.g. capelin, herring, sand eel, mackerel, anchovy and sardine, has been the standard ingredient of bulk feeds for intensively farmed fish. The strict requirements of marine fish for $n-3$ HUFA make fish oil (FO) the only commercially available source of these essential fatty acids in marine fish feeds. Until recently the ready availability and relatively low cost of FO has resulted in its widespread use in farmed fish feeds. However, global fisheries have now reached their sustainable limits and the current yield of FO from industrial fisheries, circa 1.4 million tonnes in 1996 (Sargent and Tacon, 1999), is unlikely to be significantly exceeded in future (Tacon, 2004; Pike, 2005). It is clear that the increasing demand from aquaculture for FO will soon exceed supply and threaten the viability of fish farming activities as well as wild fish stocks. For these reasons, identifying suitable alternatives to FO in farmed fish feeds or improving efficiency of FO use are becoming increasingly urgent issues. A variety of oils, particularly those derived from plant oilseeds (vegetable oils, VO) are available, however any dietary alternative to FO must address the issues of balancing lipid storage with lipid burning for growth and supplying essential fatty acids, whilst maintaining the health of the fish.

This review will focus on recent research applying molecular and genomic techniques to the study of fin-fish lipid metabolism from an aquaculture perspective. Accordingly, major emphasis will be given to fatty acid metabolism and to HUFA biosynthesis, as well as to the potential transcriptional mechanisms and factors that regulate these processes in fish. To this end, a comparative approach to mammalian fatty acid metabolism is inevitable. Although this review is focused on aquaculture species, stressing, the similarities and differences between these species in lipid biosynthesis, metabolism and storage, it also attempts to integrate relevant information stemming from genome-wide data available from sequenced fish genomes.

\section{FATTY ACID METABOLISM}

\section{Lipogenesis}

Lipogenesis in fish is considered to be essentially an identical process to that in mammals (Sheridan, 1994) and the metabolic steps are summarized in Figure 1. Thus acetyl-CoA is activated to malonyl-CoA by acetyl-CoA carboxylase (ACC) and iteratively assembled in the cytosol by fatty acid synthase (FAS) to form 16 and 18 carbon saturated fatty acids. This process requires considerable reducing power in the form of NADPH which is supplied by the dehydrogenases of the pentose phosphate shunt (principally glucose 6phosphate dehydrogenase, G6PD) and malic enzyme (ME). Thus pivotal flow through lipogenesis is controlled by two limiting supplies, NADPH and malonyl-CoA. The cellular content of G6PD and ME varies markedly depending upon dietary and hormonal conditions. In Atlantic salmon (Salmo salar), under standard diets, ME is the major 
contributor (Menoyo et al. 2003) whereas in gilthead sea bream (Sparus aurata, hereafter sea bream), NADPH is mainly provided by G6PD (Menoyo et al. 2004).

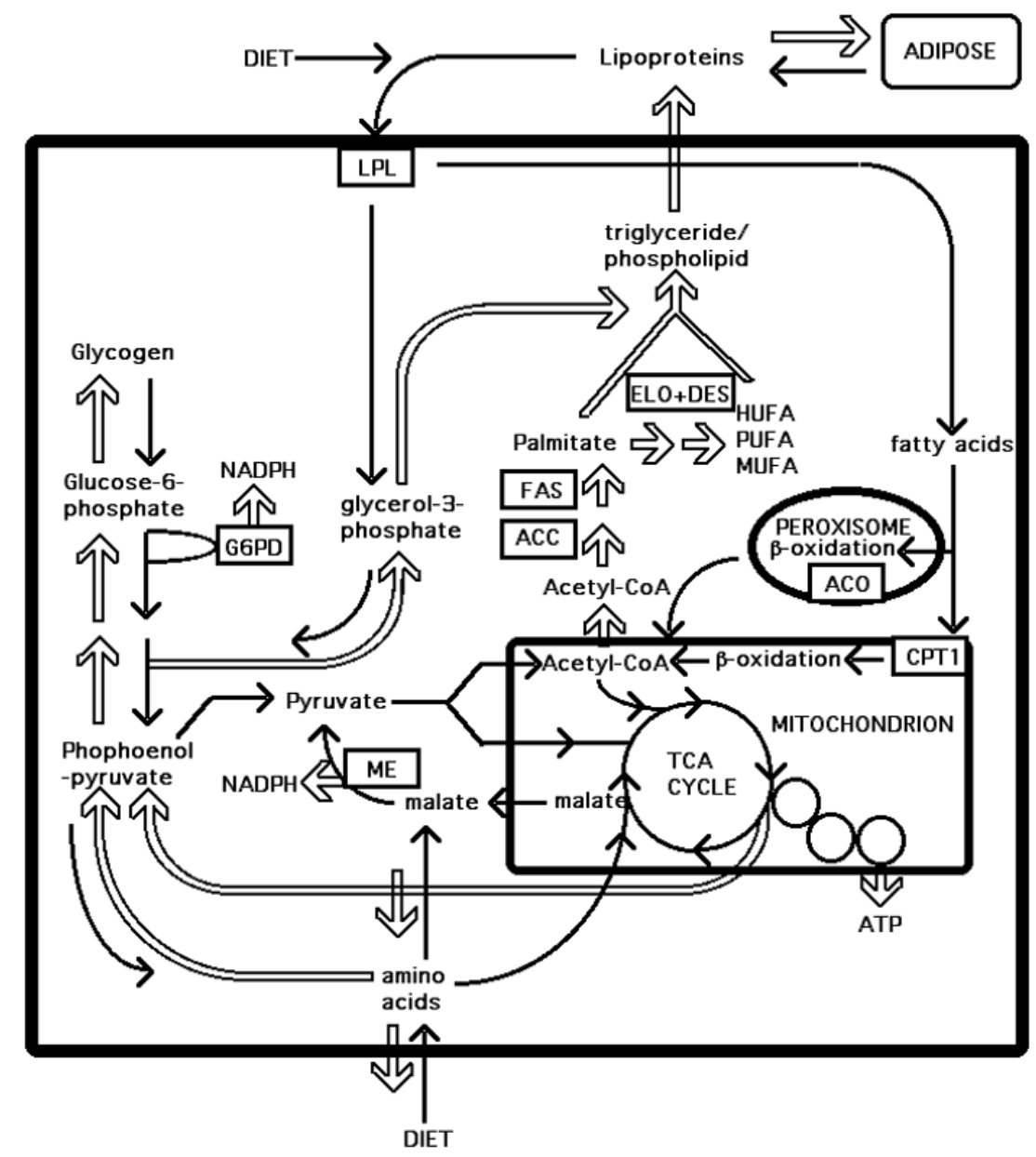

Figure 1. Schematic view of the main pathways of dietary fuel metabolism in fish liver. Some major metabolites are indicated and important enzymes discussed in the text are boxed. Open arrows indicate anabolic pathways and normal arrows catabolic routes. Diet provides fatty acids that can be directly stored in adipose tissue or enter into the hepatic pathways for energy generation though $\beta$-oxidation in peroxisomes or mitochondria. The highly regulated lipoprotein lipase (LPL) is a main distributor of the fate of fatty acids. The carnitine palmitoyl tranferase system (CPT) in the mitochondrial membrane is the limiting step in the energy use from fatty acids into the mitochondria, whilst acetyl CoA-oxidase (ACO) is a major enzyme of fatty oxidation in peroxisomes. Lipid biosynthesis (and many other biosynthetic pathways) is driven by the acetyl-CoA-carboxylase (ACC) and fatty acid synthase (FAS) coupled system which is nourished by NADPH through the pentose-phosphate shunt at glucose-6-phosphate dehydrogenase (G6PD) and by the activity of malic enzyme (ME). Highly unsaturated, polyunsaturated and monounsaturated fatty acids (HUFA, PUFA and MUFA respectively) are synthesized from cellular fatty acid intermediates (e.g. palmitate) and from dietary fatty acids though fatty acid elogase (ELO) and desaturase (DES). Dietary amino acids can be oxidized to intermediates which can enter gluconeogenic pathways, ultimately for energy storage as glycogen or for NADPH production.

Saturated 16:0 and 18:0 fatty acids assembled by FAS can then be desaturated initially by stearoyl CoA deasurase to form 16:1n-7 and 18:1n-9. These monounsaturates may be further desaturated and elongated by specific fatty acyl desaturases and elongases, 
especially under conditions of essential fatty acid deficiency (see section 2.5.1 Fatty acyl desaturases). Changes in hepatic G6PD activity levels in Atlantic salmon fed VO based diets have been connected with increases in these fatty acid elongation and desaturation processes which require NADPH (Menoyo et al. 2005; Zheng et al. 2004b). Substitution of FO for VO in fish diets has been shown to affect lipogenesis. In fish, relative NADPH contribution by ME and G6PD is controlled by the presence of particular fatty acids that modify their specific activities. Thus, EPA and DHA inhibit lipogenesis in salmonids in vivo and in vitro (Menoyo et al. 2003; Alvarez et al. 2000) indicating that the HUFA components of FO tend to repress hepatic lipogenic enzymes. Atlantic salmon in both fresh water and sea water stages (Jordal et al. 2007), exhibit lower hepatic triacylglycerol levels in FO compared to VO fed fish.. Simlarly, VO inclusion in Atlantic salmon diets results in increased liver lipid and up-regulation of the glucose transporter GLUT4 expression in muscle, with concomitant modifications of plasma triglyceride and glucose levels (Menoyo et al. 2006). In sea bream the inclusion of VO in the diet reduces the n-3 PUFA levels in muscle and this is in turn associated with a higher liver lipid deposition (Menoyo et al. 2004). The mechanism by which dietary fat type affects fat deposition and glucose metabolism in fish are not known, but somatolactin and growth hormone have been shown to inhibit ACC in sea bass highlighting the importance of hormones in regulating these processes (De Celis et al. 2003). However, although there are indications of alterations in patterns of lipid deposition, in general the substitution of FO by VO has no drastic effects on lipogenesis. This is probably because the dietary supply of fat is high in aquaculture diets. Notably, rainbow trout (Oncorhynchus mykiss) liver and intestine ACC activity is decreased by high lipid diets (Rollin et al. 2003). For these reasons there have been very few molecular studies specifically targeting lipogenesis in fish.

\section{Lipoprotein Lipase}

The fate of endogenously synthesised fatty acids is predominantly structural and as energy storage. All fish, store lipids in viscera, liver and muscle tissues (Zhou et al. 1995; Jobling and Johansen, 2003; Nanton et al. 2007). Most lipogenesis occurs in the liver and adipose cells and transport of lipid between these stores and to tissues is accomplished by assembly and excretion followed by disassembly and uptake of plasma lipoproteins. Lipoprotein lipase (LPL) is an important enzyme in this process and its differential regulation across different tissues is critical to the balance between fat accumulation and fat catabolism (Fig. 1). LPL activity is promoted in adipose tissue by hormones such as insulin, and depressed in muscle by, for example, catecholamines. Thus the activity of LPL can be regulated reciprocally between muscle and adipose tissue so as to favour either energy production or storage of TG (Mead et al. 2002). Several LPL genes have been identified in fish (Lindberg and Olivecrona, 2002; Saera-Vila et al. 2005; Oku et al. 2002). The four LPL genes found in red sea bream (Pagrus major), named LPL1, LPL2, HL (hepatic lipase) and PL (pancreatic lipase) have a high degree of sequence similarity. LPL1 and LPL2 genes are ubiquitously expressed but HL is exclusively expressed in hepatic tissue and PL in hepatopancreas and adipose tissue. The ubiquitous LPL1 and LPL2 genes are regulated in a tissue-specific manner in response to the nutritional state of fish (Oku et al. 2006), and recently some knowledge on how 
nutritional and seasonal status and hormones affect these genes have been obtained in several fish. Starvation increases, and dietary fatty acids differentially regulate LPL expression in red sea bream liver and adipose tissue (Liang et al. 2002; Oku et al. 2006). In rainbow trout adipose LPL activity is regulated by insulin with tissue-specific modulation following food intake (Albalat et al. 2006). Moreover, TNF $\alpha$, a cytokine with many biological functions that in mammals modulates muscle and adipose tissue metabolism, plays an important role in the control of lipid metabolism in rainbow trout by down-regulating adipose tissue LPL activity and also by stimulating lipolysis (Albalat et al. 2006). Seasonal- and nutritional-dependent tissue-specific regulation of ubiquitous LPL also occurs in gilthead sea bream (Saera-Vila et al. 2005). In these studies, maximal expression of LPL was found in mesenteric adipose tissue and up-regulation of this gene in spring coincides with a pronounced increase of whole body fat content. In contrast, in summer skeletal muscle LPL expression peaks to facilitate the increased energy demands for muscle growth through structural protein accumulation (Saera-Vila et al. 2005). These studies have underlined the importance of endocrine control of fish energy homeostasis, which regulates lipid catabolism as a response to different seasonal or nutritional situations.

\section{Beta-oxidation of Fatty Acids}

The catabolism of fatty acids can occur by $\beta$-oxidation in two different organelles in the cells, mitochondria and peroxisomes (Fig. 1). Red muscle, liver and heart are generally regarded as the most important tissues for $\beta$-oxidation in fish (reviewed by (Henderson and Tocher, 1987). However, although having a low $\beta$-oxidation capacity per gram of tissue, white muscle has been shown to be the major site for $\beta$-oxidation due to the overall size of the tissue (Froyland et al. 2000; Nanton et al. 2003; Stubhaug et al. 2005). The capacity for fish to catabolise fatty acids depends on various factors such as fish size, life stage and season with especially smoltification in Atlantic salmon having a major impact on $\beta$-oxidation capacity in liver and red muscle (Stubhaug et al. 2006). Carnivorous fish rely mainly on protein and lipids for energy rather than carbohydrates. The relative importance of dietary lipid for energy production compared to protein is dependent on dietary lipid level with high dietary lipid having a protein sparing effect (Hemre and Sandnes, 1999).

Peroxisomal $\beta$-oxidation resembles mitochondrial $\beta$-oxidation, however different enzymes perform the various reactions and consequently half of the energy produced from peroxisomal $\beta$-oxidation is lost as heat compared to mitochondrial $\beta$-oxidation. The importance of mitochondrial or peroxisomal $\beta$-oxidation is dependent on tissue. Typically in fish liver peroxisomal $\beta$-oxidation contributes significantly to the total $\beta$-oxidation capacity (Crockett and Sidell, 1993; Nanton et al. 2003), and contributes up to $100 \%$ of the total $\beta$-oxidation during the parr-smolt transformation (Stubhaug et al. 2007). The contribution from peroxisomal $\beta$-oxidation is low and less than $10 \%$ of the total in both white- and red muscle in Atlantic salmon, but increases up to $60 \%$ in red muscle during Atlantic salmon parr-smolt transformation (Stubhaug et al. 2007). Acyl-CoA oxidase (ACO, Fig. 1) catalyzes the rate limiting step in the peroxisomal $\beta$-oxidation system (Inestrosa et al. 1979). ACO genes have been studies in fish and are similar in sequence and tissue expression to their mammalian counterparts. Notably, expression of ACO in 
rainbow trout is nutritionally regulated, with intestinal mRNA levels rising in response to feeding (Morais et al. 2007). Given the importance of peroxisomal $\beta$-oxidation in Atlantic salmon, several studies have attempted to investigate ACO activity in liver (see later section on PPAR $\alpha$ ) and in general these studies have not shown large changes, either after FO substitution or after feeding compounds shown to be modulators of ACO activity in rodents (Henderson and Sargent, 1984; Donohue et al. 1993; Ruyter et al. 1997). A notable exception occurs during the Atlantic salmon parr-smolt transformation where VO-fed fish had significantly decreased $\beta$-oxidation capacity compared to FO-fed fish (Stubhaug et al. 2007). Also of interest is the finding that feeding of sea bream with conjugated linoleic acid (CLA)-supplemented FO diets (Diez et al. 2007) stimulated a large postprandial (6 hours after feeding) increase in ACO activity compared to FO alone and furthermore this effect was accompanied by a decrease in a marker of mitochondrial $\beta$-oxidation, L-3-hydroxyacyl-CoA dehydrogenase. Interestingly these effects of CLA on sea bream were not observed 24 hours after feeding, indicating that the measurement of postprandial effects should be given more attention in future FO replacement experiments.

Replacing dietary FO with plant oils and thus significantly changing the dietary and tissue fatty acid composition may also influence the $\beta$-oxidation capacity (Torstensen and Stubhaug, 2004; Stubhaug et al. 2006; Stubhaug et al. 2007). These studies suggest that there are $\beta$-oxidation substrate preferences for some fatty acids which differ between fish fed FO and VO. The mechanisms of these dietary induced changes in $\beta$-oxidation in fish are unknown.

\section{Carnitine palmitoyl transferase}

To enable mitochondrial $\beta$-oxidation of the activated fatty acid, acyl-CoAs have to reach the inner compartment of the mitochondria. Carnitine palmitoyl transferase-1 (CPT1, Fig.1) in the outer mitochondria membrane converts acyl-CoA to acyl-carnitine, which is then transported over the inner mitochondrial membrane in exchange with a free carnitine molecule. Inside the mitochondrial matrix acyl-carnitine is converted back to acyl-CoA by the action of carnitine palmitoyl transferase-2 (CPT2), and the acyl-CoA is then $\beta$-oxidised. Generally, the key point in the regulation of mitochondrial $\beta$-oxidation is thought to be CPT1, which can be inhibited by malonyl-CoA. Since the synthesis of malonyl-CoA is the first committed step in de novo fatty acid biosynthesis, the concentration-dependent inhibition of CPT1 by malonyl-CoA provides a direct mechanism to control the balance between lipogenesis and mitochondrial $\beta$-oxidation (Bremer, 1997). In addition to inhibition by malonyl-CoA, CPT1 activity is significantly regulated at the gene level as a response to nutritional stimuli such as fatty acids and feeding and fasting (Brandt et al. 1998; Leone et al. 1999). In mammals, CPT1 exists as at least two isoforms, one being expressed predominantly in the liver (CPT1A) and the second (CPT1B) in the skeletal muscle. A third more distantly related isoform of the enzyme (CPT1C) of unknown function and whose expression is restricted to the central nervous system, has been recently described in mammals (Van Der Leij et al. 2000; Price et al. 2002). The genetics underlying the CPT system in fish have recently attracted some attention. A cDNA encoding the apparent CPT1B orthologue of rainbow trout has been reported (Gutieres et al. 2003). Although the inhibition of CPT1 by malonyl-CoA 
has been confirmed for Atlantic salmon (Froyland et al. 1998) and rainbow trout (Gutieres et al. 2003), the data presently available for the regulation of this enzyme at the gene level in fish are limited. Hepatic CPT1 activity and mRNA expression have been reported not to be affected by dietary CLA in Atlantic salmon, despite a significant increase in peroxisomal $\beta$-oxidation in the liver as a response to this treatment (Leaver et al. 2006). In contrast, in red muscle CPT1 activity and mRNA levels significantly decreased with dietary CLA intake (Leaver et al. 2006). Furthermore, we have also observed a significant post-prandial decrease of CPT1B mRNA levels in the sea bream heart (M. J. Leaver and G. Krey, unpublished).

Although CPT2 may also act as an important regulation site in rodent lipid metabolism (Willumsen et al. 1996; Madsen and Berge, 1999), this gene and its product have not been studied in fish. The same also holds for a variety of other enzymes important for mitochondrial $\beta$-oxidation and energy transduction, such as the long-chain acyl-CoA-dehydrogenase, a key enzyme of mitochondrial $\beta$-oxidation of unsaturated fatty acids (Le et al. 2000). It is evident that the molecular aspects of mitochondrial $\beta$ oxidation must be more thoroughly examined in fish.

\section{Biosynthesis of Highly Unsaturated Fatty Acids}

All organisms are capable of lipogenesis, that is, the synthesis of saturated fatty acids, and the production of monounsaturated fatty acids (such as 18:1n-9) via the action of $\Delta 9$ desaturases. However, only plants (and a few invertebrates) have the $\Delta 12$ and $\Delta 15$ ( $\omega 3$ ) desaturases necessary to further desaturate 18:1n-9 to form the polyunsaturated fatty acids (PUFA), 18:2n-6 and 18:3n-3, respectively. Therefore, PUFA are essential in the diet of vertebrates as precursors of the physiologically essential HUFA; EPA, DHA and arachidonic acid (ARA; 20:4n-6). In vertebrates, biosynthesis of HUFA can proceed by sequential desaturation and elongation of 18:2n-6 and 18:3n-3 in the endoplasmic reticulum. Synthesis of ARA is achieved by $\Delta 6$ desaturation of $18: 2 n-6$ to produce $18: 3 n-6$ that is elongated to $20: 3 n-6$ and finally desaturated at the $\Delta 5$ position to produce ARA (Fig 2.; Cook, 1996). The pathway for EPA synthesis from 18:3n-3 is essentially similar but, for DHA synthesis, the insertion of the last $\Delta 4$ ethylenic bond does not occur through direct $\Delta 4$ desaturation. Rather, EPA undergoes two rounds of elongation to form 24:5n-3 which then undergoes $\Delta 6$ desaturation $\left(\Delta 6^{*}\right)$ to $24: 6 n-3$ followed by a chain shortening reaction in the peroxisomes, to 22:6n-3 (Fig.2; Sprecher, 2000).

The extent to which fish can convert $\mathrm{C}_{18}$ PUFA to $\mathrm{C}_{20 / 22}$ HUFA varies, associated with their complement of fatty acid desaturase and elongase enzymes. Freshwater fish are capable of producing DHA from 18:3n-3 and so presumably express all the desaturase and elongase activities necessary for this biosynthetic pathway (Sargent et al. 2002). In contrast, marine fish are unable to produce DHA from 18:3n-3 at a physiologically significant rate (Sargent et al. 2002) due to deficiencies in one or more steps in the pathway (Tocher, 2003). These differences in the capacity of fish to synthesise HUFA appear to be evolutionarily related to the nature of the fatty acid profiles present in their respective diets. Thus, freshwater fish, whose diets are based on the terrestrial food chain which is generally lower in HUFA and particularly DHA, convert $18: 2 n-6$ and $18: 3 n-3$ to HUFA more efficiently than do marine species whose 
diet is rich in both EPA and DHA characteristic of the phytoplanktonic organisms on which the marine food chain is built (Sargent et al. 2002; Tocher, 2003). The consequence is that $18: 2 n-6$ and $18: 3 n-3$ can satisfy essential fatty acid (EFA) requirements in freshwater fish, whereas EPA and DHA are the required essential fatty acids in marine fish (Sargent et al. 2002).

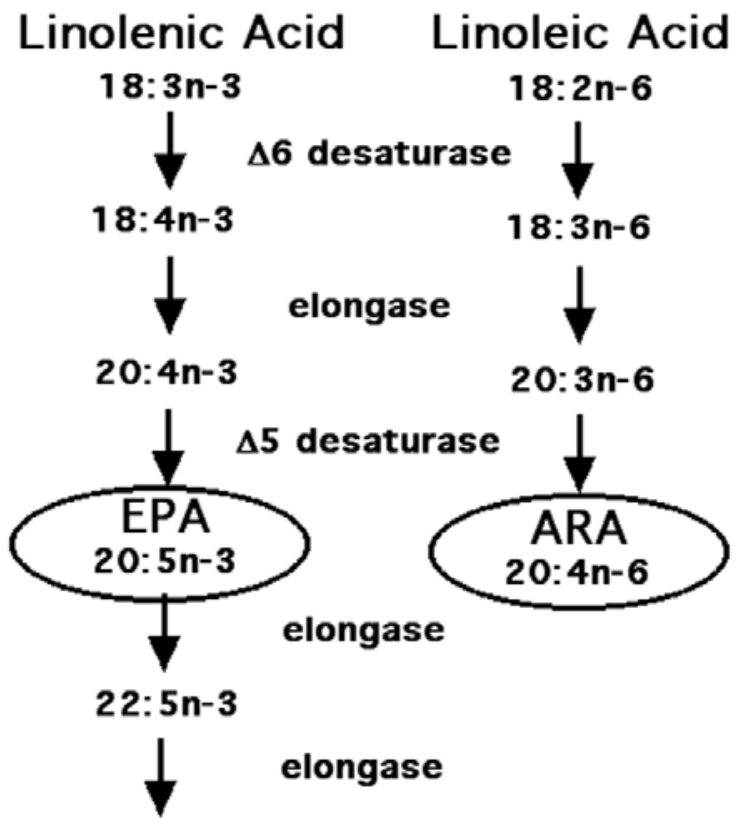

24:5n-3

$\downarrow \Delta 6^{*}$ desaturase

24: $6 n-3$

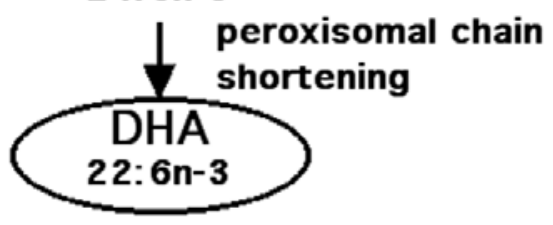

Figure 2.The highly unsaturated fatty acid biosynthesis pathway in vertebrates.

Schematic pathway showing the enzymes and intermediate fatty acids catalysing and leading to the predominant products of highly unsaturated fatty acid synthesis in vertebrates. ARA, arachidonic acid; EPA, eicosapentenoic acid and DHA, docosahexenoic acid.

Aquaculture supplies an increasing proportion of the fish in the human food basket, up to $43 \%$ in 2005 (FAO, 2006). So far artificial diets, traditionally based on FO, have ensured that farmed fish, particulary of marine origin, are rich in n-3 HUFA. The principal sustainable alternatives to $\mathrm{FO}$ are numerous plant-derived $\mathrm{VO}$, which can be rich in $\mathrm{C}_{18}$ PUFA, but lack the n-3HUFA abundant in FO (Sargent et al. 2002). Thus, flesh fatty acid compositions of fish fed VO are characterised by increased levels of 18:2n-6 and 18:3n-3, and decreased levels of n-3 HUFA, compromising their nutritional value to the human consumer (Izquierdo et al. 2003; Regost et al. 2003). The primary objectives in applying genomic and molecular technologies to this area are to identify the genes encoding HUFA biosynthetic enzymes, to determine how they are regulated and how their expression can be optimised to enable fish to make effective use of dietary VO.

Fatty acyl desaturases 
Mammals possess separate genes for $\Delta 5$ and $\Delta 6$ desaturases (Marquardt et al. 2000) and can produce DHA from 18:3n-3 endogenously, albeit at low levels (Bezard et al. 1994). These genes encode endoplasmic reticulum bound proteins, each of around $52 \mathrm{kDa}$, which act as the substrate-specific terminal components of an electron transport system. They have a requirement for NADPH and molecular oxygen and insert double bonds between the carboxyl end and the first pre-existing double bond of fatty acids of between 16 and 24 carbons, a characteristic which accounts for the name "front-end" desaturases (Tocher et al. 1998). The protein sequences of the fish desaturases possess all the characteristic features of microsomal fatty acid front-end desaturases from other organisms, including three histidine boxes, two transmembrane regions, and an Nterminal cytochrome $b_{5}$ domain containing the haem-binding motif, HPGG. Thus the fish desaturases, like all others known, are proteins containing both desaturase and cytochrome $b_{5}$ functions.

Piscine fatty acid desaturases were first cloned from zebrafish (Danio rerio) and rainbow trout using PCR techniques (Hastings et al. 2001; Seiliez et al. 2001). Functional characterisation of the zebrafish desaturase by heterologous expression in the yeast Saccharomyces cerevisiae showed the enzyme to have both $\Delta 6$ and $\Delta 5$ desaturase activity. In this the zebrafish desaturase is unique, possessing the only bifunctional desaturase involved in HUFA synthesis so far isolated, not only in fish, but in vertebrates in general. Furthermore, this desaturase is the only PUFA desaturase represented in the zebrafish genome. The zebrafish desaturase also shows a low level of activity towards $\mathrm{C}_{24}$ fatty acid substrates suggesting that it also has $\Delta 6^{*}$ activity (see Fig. 2). In contrast, desaturase cDNAs from other freshwater fish, including rainbow trout and common carp (Cyprinus carpio) encode unifunctional $\Delta 6$ desaturases (Zheng et al. 2004a). However, separate cDNAs for $\Delta 6$ and $\Delta 5$ desaturases have been cloned from Atlantic salmon (Hastings et al. 2004; Zheng et al. 2005a), indicating the presence of multiple desaturase genes in at least some fish. To date, only $\Delta 6$ desaturase cDNAs have been cloned from marine fish, including gilthead sea bream, turbot (Psetta maximus) and cod (Gadus morhua) (Seiliez et al. 2003; Zheng et al. 2004a; Tocher et al. 2006). All fish desaturases are more active towards the n-3 fatty acid substrate than the equivalent n-6 substrate (Table 1). The Atlantic salmon $\Delta 5$ and $\Delta 6$ cDNAs are very similar, sharing greater than $95 \%$ nucleic acid identity, indicating the presence of a recently duplicated locus, probably as the result of the recent salmonid tetraploidisation (Allendorf and Thorgaard, 1984). The full genomic sequence has only been reported for the Atlantic salmon $\Delta 6$ desaturase with 13 exons spanning 7965 bp of genomic DNA (Zheng et al. 2005a).

The presence of two separate genes for $\Delta 5$ and $\Delta 6$ desaturase in Atlantic salmon is consistent with the biochemical evidence for the production of DHA from 18:3n-3 in this species. Similarly, the presence of a bifunctional $\Delta 5 / \Delta 6$ desaturase in the zebrafish genome also suggests that this species can produce DHA from 18:3n-3. The apparent inability of sea bream to produce DHA from 18:3 may be explained by the presence of only a single unifunctional $\Delta 6$ desaturase gene in this species. Thus the inability of some species to produce DHA might be explained by the lack of a gene encoding $\Delta 5$ activity, a deficiency which has no significant consequence in the HUFA-rich marine ecosystem. In 
Table 1. Functional characterisation of fish fatty acyl desaturase cDNAs

\begin{tabular}{|c|c|c|c|c|c|c|c|c|c|c|c|c|c|c|c|c|}
\hline & \multicolumn{2}{|c|}{$\begin{array}{c}\text { Zebrafish } \\
\Delta 5 / \Delta 6\end{array}$} & \multicolumn{2}{|c|}{$\begin{array}{c}\text { Carp } \\
\Delta 6\end{array}$} & \multicolumn{2}{|c|}{$\begin{array}{l}\text { R. trout } \\
\qquad 6\end{array}$} & \multicolumn{2}{|c|}{$\begin{array}{l}\text { Salmon } \\
\quad \Delta 5\end{array}$} & \multicolumn{2}{|c|}{$\begin{array}{l}\text { Salmon } \\
\Delta 6\end{array}$} & \multicolumn{2}{|c|}{$\begin{array}{c}\text { Sea bream } \\
\Delta 6\end{array}$} & \multicolumn{2}{|c|}{$\begin{array}{l}\text { Turbot } \\
\Delta 6\end{array}$} & \multicolumn{2}{|c|}{$\begin{array}{l}\text { Cod } \\
\Delta 6\end{array}$} \\
\hline & $n-3$ & $\mathrm{n}-6$ & 3 & $n-$ & $n-3$ & $\mathrm{n}$ & -3 & $n-6$ & 3 & $n-6$ & -3 & $n-6$ & $n-3$ & $n-6$ & $1-3$ & $n$ \\
\hline & & & & & & & & & & & & & & & J & \\
\hline & & & & & & 0 & & & & & & & & & & \\
\hline$\triangle 4$ & 0. & 0.0 & 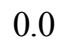 & 0. & nd & 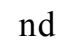 & 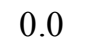 & 0. & & 0.0 & & 10 & 0.0 & 0.0 & 0.0 & 0.0 \\
\hline$\Delta 6^{*}$ & $\sim 5$ & $\sim 2$ & nd & nd & nd & nd & 0.0 & 0.0 & 0.0 & 0.0 & nd & nd & nd & nd & nd & nd \\
\hline
\end{tabular}

Results are presented as percentage of substrate fatty acid converted to elongated product. Fatty acid substrates are: $\Delta 6,18: 3 n-3$ and $18: 2 n-6 ; \Delta 5,20: 4 n-3$ and $20: 3 n-6 ; \Delta 4,22: 5 n-3$ and $22: 4 n-6 ; \Delta 6^{*}$, 24:5n-3 and 24:4n-6; nd, not detected.

contrast, the bifunctional zebrafish gene and multiple subfunctionalized salmon genes have enabled these species, which spend all or a significant part of their lifecycles in relatively nutrient-poor riverine environments, to produce essential HUFA. These conclusions are supported by searches of sequenced fish genomes and phylogenetic sequence analysis which, in agreement with classical phylogeny (Nelson, 2006), group the above fish desaturases in three distinct clusters. The first includes the common carp and zebrafish sequences (Ostariophysi), the second the rainbow trout and Atlantic salmon sequences (Salmoniformes), and the third the tilapia (Oreochromis nilotica), sea bream, turbot, stickleback (Gasterosteus aculeatus) and medaka (Oryzias latipes) sequences (Acanthopterygia) with the cod (Paracanthopterygii) branching from the Acanthopterygia line (Fig.3A). Within the three sequenced Acanthopterygii genomes, the medaka possess a single HUFA desaturase, the stickleback two very closely related genes and searches of the pufferfish (both Tetraodon nigroviridis and Takafugu rubripes; Acanthopterygii) genomes fail to identify any $\Delta 5 / \Delta 6$ homologues (Fig3A).

These considerations have clear implications for the formulation and suitability of aquaculture feeds containing HUFA-deficient alternatives to FO, and current research is aimed at determining the distribution of $\Delta 5$ and $\Delta 6$ desaturase genes across phyla and in understanding the regulation of their expression.

\section{Fatty acyl elongases}

Very long chain fatty acyl elongase (ELOVL; Elongation of Very Long chain fatty acids) genes, like the fatty acyl $\Delta 5$ and $\Delta 6$ desaturases, are endoplasmic reticulum bound proteins and several distinct elongases have been characterized each with activity toward different fatty acid substrates (Jakobsson et al. 2006). ELOVLs condense long chain acyl-CoA with malonyl-CoA, thus acting as the substrate-specific components of a multienzyme pathway, which also includes ketoreductase, dehydratase and enolase and requires NADPH. Thus ELOVL belongs to a multicomponent enzyme system of the endoplasmic reticulum analogous to the single component, multi-activity cytosolic fatty acid synthase of vertebrates (Jakobsson et al. 2006). In mammals, these genes are now termed ELOVL1 to 7 to indicate different substrate specificities and of these at least ELOVL2 and ELOVL5 have been shown to participate in HUFA biosynthesis (Leonard et al. 2000; Leonard et al. 2002; Jakobsson et al. 2006). 
A

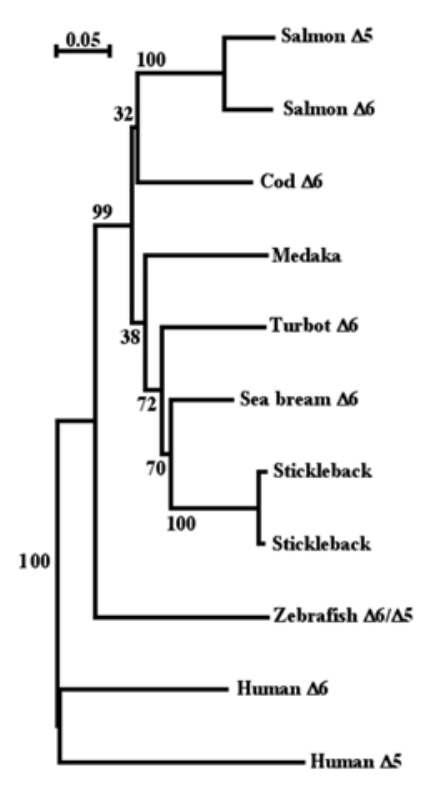

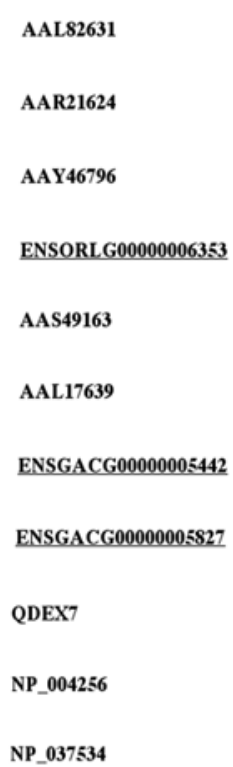

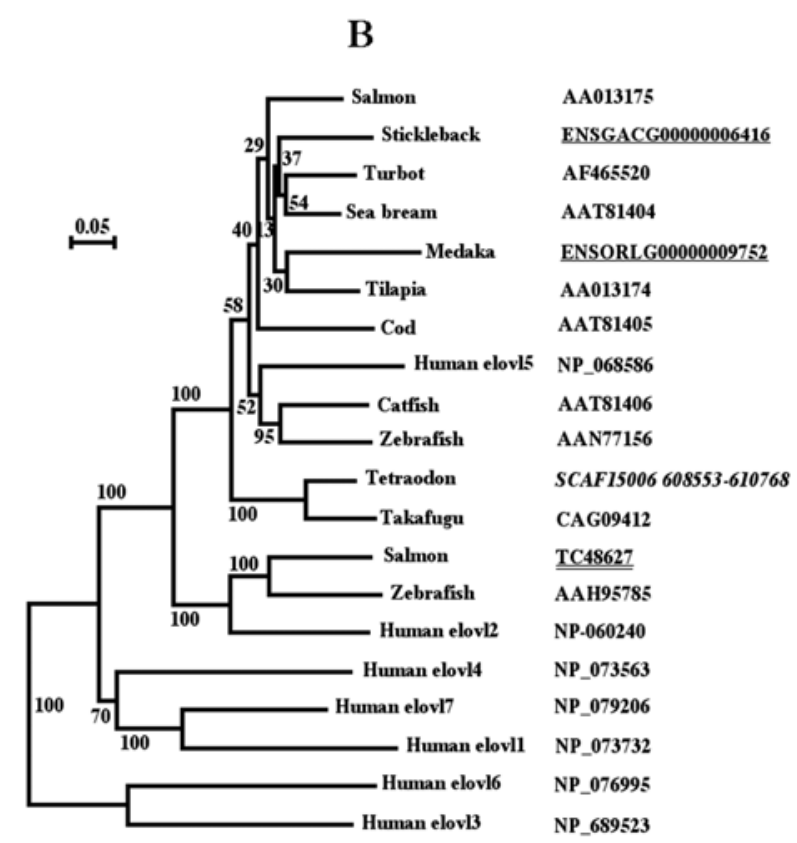

Figure 3. Molecular phylogeny of fish and human highly unsaturated fatty acyl desaturases and elongases. Panel A: Phylogeny of vertebrate desaturases. Panel B: Phylogeny of vertebrate elongases. Desaturase and elongase sequences were obtained from the NCBI/EMBL databases or were derived from genomic sequence information by searching (TBLASTN) with zebrafish $\Delta 5 / \Delta 6 \mathrm{cDNA}$ sequence. All sequences were aligned and neighbour joining trees derived and bootstrapped using ClustalX. Resulting unrooted trees were plotted with NJplot. Numbers at nodes indicate the percentage frequency with which the tree topology was returned after bootstrapping the multiple alignment data through 1000 iterations. NCBI/EMBL protein sequence accession numbers are shown in normal text. ENSEMBL (www.ensembl.org) gene identification numbers are shown in italics for protein sequences derived from sequenced fish genomes. The accession number for an assembly of various salmon EST sequences from www.tigr.org is double underlined.

ELOVL cDNAs of the HUFA biosynthetic pathway have been cloned from a number of fish: the freshwater species zebrafish, common carp and tilapia, the salmonids, Atlantic salmon and rainbow trout, and the marine species cod, turbot and sea bream (Hastings et al. 2004; Agaba et al. 2004; Agaba et al. 2005). These cDNAs encode putative open reading frames (ORFs) of 288-294 amino acids that are highly conserved among the fish. The predicted elongase polypeptides share characteristic features of microsomal ELOVLs, including a single histidine box redox centre motif, a canonical ER retention signal (carboxyl-terminal dilysine targeting signal) and multiple transmembrane regions. (Meyer et al. 2004). Phylogenetic analysis comparing all the putative ELOVL sequences identified from fish, along with a range of ELOVLs from mammals (Fig 3B), group the fish elongase cDNAs into a closely related cluster with greatest similarity to mammalian ELOVL5. Interestingly all of the fish ELOVLs tested by heterologous expression in yeast exhibit the ability to lengthen $n-3$ and n-6 PUFA and monounsaturated substrates with chain lengths from $\mathrm{C}_{18}$ to $\mathrm{C}_{22}$ (Table 2). ELOVL5, the mammalian subtype most similar to all characterized piscine elongases, is predominantly involved in the elongation of C18 and C20 PUFA (Leonard et al. 2000), whilst mammalian ELOVL2 has greatest activity in the elongation of C20 and C22 (Leonard et al. 2002). Notably the zebrafish genome and the Atlantic salmon EST database 
(www.tigr.org) both contain a second PUFA elongase gene which is clearly related to ELOVL2 (Fig 3B.). The substrate specificities of these gene products have not yet been tested. Although the analysis of fish ELOVL genes is not yet exhaustive, it is clear that the pufferfish, stickleback and medaka and thus probably all other Acanthopterygii do not possess ELOVL2 homologues and it is likely that the characterized elongase cDNAs of sea bream and turbot are the sole representatives of a PUFA ELOVL gene in these species. Thus the varying competences of different fish to biosynthesize HUFA would not only depend on their genome complement of desaturase genes but also elongases.

Table 2. Functional characterisation of fish fatty acyl elongase cDNAs

\begin{tabular}{ccccccccccccccc}
\hline & \multirow{2}{*}{ Zebrafish } & \multicolumn{2}{c}{ Catfish } & \multicolumn{2}{c}{ Tilapia } & \multicolumn{2}{c}{ Salmon } & \multicolumn{3}{c}{ Turbot } & \multicolumn{3}{c}{ Sea bream } & \multicolumn{2}{c}{ Cod } \\
& $\mathrm{n}-3$ & $\mathrm{n}-6$ & $\mathrm{n}-3$ & $\mathrm{n}-6$ & $\mathrm{n}-3$ & $\mathrm{n}-6$ & $\mathrm{n}-3$ & $\mathrm{n}-6$ & $\mathrm{n}-3$ & $\mathrm{n}-6$ & $\mathrm{n}-3$ & $\mathrm{n}-6$ & $\mathrm{n}-3$ & $\mathrm{n}-6$ \\
\hline $\mathrm{C}_{18-20}$ & 85.4 & 70.7 & 87.5 & 78.3 & 82.6 & 71.2 & 71.8 & 42.1 & 49.0 & 22.8 & 85.9 & 84.3 & 7.4 & 15.7 \\
$\mathrm{C}_{20-22}$ & 49.4 & 25.6 & 48.1 & 40.8 & 86.6 & 61.8 & 38.9 & 22.6 & 39.3 & 21.3 & 66.8 & 43.9 & 0.8 & 1.5 \\
$\mathrm{C}_{22-24}$ & 4.9 & 0.5 & 2.8 & 0.9 & 1.0 & $\mathrm{tr}$ & 0.7 & 0.3 & 0.6 & 0.6 & 4.7 & 0.8 & $\mathrm{nd}$ & $\mathrm{nd}$ \\
\hline
\end{tabular}

Results are presented as percentage of substrate fatty acid converted to elongated product. Fatty acid substrates are: C18-20, 18:4n-3 and 18:3n-6; C20-22, 20:5n-3 and 20:4n-6; C22-24, 22:5n-3 and 22:4n-6; nd, not detected; tr, trace $(<0.05 \%)$.

\section{Tissue Distributions and Nutritional Regulation}

Both fatty acyl $\Delta 5$ and $\Delta 6$ desaturase and elongase are most highly expressed in intestine, followed by liver and brain, with much lower levels in other tissues (Zheng et al. 2005a). Similarly, $\Delta 6$ desaturase expression in rainbow trout is high in liver, intestine and brain and low in kidney, heart and white muscle (Seiliez et al. 2001). In cod, $\Delta 6$ desaturase and PUFA elongase genes are most highly expressed in brain with high levels also in liver kidney and intestine (Tocher et al. 2006). In sea bream, elongase expression is highest in liver and intestine, with lower levels in brain and gills. Sea bream desaturase expression, like Atlantic salmon and cod, is expressed to high level in liver and brain, but in contrast to Atlantic salmon and cod is relatively low in intestine (Diez et al. 2007).

Genes of the HUFA biosynthetic pathway are also regulated in response to substituion of FO by VO. The expression of $\Delta 5$ desturase and elongase genes is positively and negatively correlated with dietary 18:3n-3 and n-3 HUFA content, respectively when Atlantic salmon are fed a linseed oil (high 18:3n-3) based diet for 20 weeks. After 40 weeks feeding the activity of the HUFA biosynthetic pathway, is positively and significantly correlated with dietary linseed oil. Similarly, the $\Delta 5$ desaturase gene is up-regulated in Atlantic salmon fed 75\% rapeseed oil compared to fish fed FO (Jordal et al. 2005). At various points during the entire two year production cycle in Atlantic salmon fed diets containing either $100 \% \mathrm{FO}$ or diets where $75 \%$ and $100 \%$ of FO was replaced by a VO blend (Zheng et al. 2005b), expression of $\Delta 6$ desaturase mRNA is consistently highest around the point of seawater transfer and lowest during the seawater phase. In addition, the expression of both $\Delta 6$ and $\Delta 5$ desaturase 
mRNAs is generally higher in fish fed the VO-substituted diets compared to fish fed FO, particularly in the seawater phase. These results are consistent with HUFA biosynthesis, which varies during the growth cycle with peak activity around seawater transfer and subsequent low activities in seawater, and is invariably higher in fish fed the VO blends compared to fish fed FO. The expression of PUFA elongase mRNA is not affected by VO inclusion in FO diets. These studies show that both nutritional and environmental modulation of HUFA biosynthesis in Atlantic salmon involves regulation of fatty acid desaturase gene expression, with desaturase gene expression being higher during the transition from freshwater to seawater and when fed with diets containing reduced HUFA.

The expression of the $\Delta 6$ desaturase gene in the marine sea bream is apparently increased several-fold in liver of fish fed rapeseed, linseed or soybean oil as determined by RNase protection (M. J Leaver, G. Krey, unpublished). Similar to sea bream, expression of the $\Delta 6$ desaturase gene in sea bass liver tends to increase in diets containing rapeseed oil, olive oil and, especially, linseed oil and is significantly upregulated in liver of fish fed a VO blend.

In contrast, the expression of freshwater rainbow trout $\Delta 6$ desaturase mRNA in liver is not significantly affected by dietary VOs, including linseed oil, rapeseed oil, olive oil, and a VO blend (Seiliez et al. 2003). Taken together these results suggest that marine fish or salmonids in the seawater phase are capable of up-regulating HUFA biosynthetic genes and their corresponding activities in response to reductions of HUFA in the diet. The extent to which such increases can compensate for the reduction in dietary HUFA in VO replacement of FO is as yet unquantified but may vary substantially between Atlantic salmon and marine species such as sea bream and sea bass.

\section{TRANSPORT OF FATTY ACIDS}

Fatty acids are transported between tissues largely as triglycerides and phospholipids incorporated into the lipoproteins of the plasma. Specific mechanisms exist in tissue for the uptake and excretion of particular lipoproteins and whilst these have not been extensively studied in fish, the activity of lipoprotein lipase (see previous section) is an important control point, as are the actions of cellular transport proteins.

\section{Cellular uptake of fatty acids}

In vitro studies with Atlantic salmon hepatocytes also indicate that long-chain n-3 PUFA may stimulate total $\beta$-oxidation through increased uptake of fatty acids into the cells rather than stimulating the actual $\beta$-oxidation system (Torstensen and Stubhaug, 2004).

Unesterified fatty acids can either be transported into cells through a simple diffusion mechanism regulated mainly by lipid physical chemistry (Hamilton, 1998), or by a protein mediated transport of fatty acids across the cell membrane. The latter mechanism involves a membrane-bound fatty acid transport protein (FATP), which has been identified in several tissues in rodents and mammals (Frohnert and Bernlohr, 2000). FATP cloned from mouse are reported to have very long chain acyl-CoA synthetase activity suggesting a fatty acid uptake via esterification coupled influx (Herrmann et al. 
2001). Studies of FATP in fish are scarce, however one study in rainbow trout show that fatty acid uptake is carrier-mediated in both red- and white muscle (Richards et al. 2004). It has recently been suggested that it is the metabolic demand for fatty acids that is the driving force for fatty acid uptake, through conversion of fatty acids to acyl-CoA, by the action of acyl-CoA synthetases and the regulation of the membrane bound transport proteins (Mashek and Coleman, 2006). The mitochondrial acyl-CoA synthetase has been studied in Antarctic notothenioid fish, reporting substrate specificity for unsaturated fatty acids over 16:0 and 22:6n-3 (Grove and Sidell, 2004), however molecular studies have not been done on fish acyl-CoA-synthetases.

\section{Intracellular Fatty Acid Binding Proteins}

Cytosolic fatty acid binding protein (FABP) may act as an acceptor for fatty acids that have been transported across the membrane. The FABP are low molecular mass (14$16 \mathrm{kDa})$ soluble proteins that non-covalently bind long chain fatty acids and other small organic hydrophobic molecules. They belong to a multigene family of intracellular lipidbinding proteins (iLBP) that also includes cellular retinol and retinoic acid binding proteins. Specific FABP have been found in various cell and tissue types (Matarese et al. 1989; Hertzel and Bernlohr, 2000) and it is generally considered that the FABPs fullfil specialised roles in cells where they are expressed, but definitive proof has not been forthcoming. For example, heart FABP is considered to shuttle fatty acids from the plasma membrane to mitochondria for $\beta$-oxidation while the adipocyte FABP is considered to facilitate efflux of lipolytically-derived fatty acids (Londraville and Sidell, 1996; Coe and Bernlohr, 1998). In rat heart and muscle there is a clear correlation between fatty acid oxidation and cytosolic FABP content (Veerkamp and Vanmoerkerk, 1993; Furuhashi et al. 2002).

In sunfish the expression of heart FABP is increased relative to control after injections of murine leptin (Londraville and Duvall, 2002), suggesting a central role of FABP in lipid metabolism, especially in fish fed high lipid diets. Furthermore intracellular FABP concentrations are reported to increase in response to cold acclimation (Londraville and Sidell, 1996), which is correlated with increased $\beta$-oxidation.

In Atlantic salmon the levels of FABP3 (isofrom 3) mRNA are approximately 100 fold higher in red muscle compared to white muscle, which may be correlated with higher $\beta$-oxidation capacity and fatty acid metabolism activity in red muscle (Jordal et al. 2006). In addition, protein levels of FABP3 in red and white muscle increase after replacing dietary FO with rapeseed oil (Jordal et al. 2006), which again correlates with increased $\beta$-oxidation capacity (Stubhaug et al. 2005). However, FABP3 protein levels in Atlantic salmon muscle do not correlate with FABP3 mRNA levels during a long-term feeding study (Jordal et al. 2006).

\section{ROLE OF FATTY ACIDS IN GENE REGULATION}

Fatty acids and their derivatives are known to directly regulate the activities of a variety of transcription factors whose functions are in the control of genes responsible for fatty acid, cholesterol and carbohydrate metabolism (Jump, 2004). These transcription 
factors include sterol regulatory element binding proteins (SREBP), hepatic nuclear factor4 (HNF4), liver X receptor (LXR), farnisoid X receptor (FXR) and the peroxisome proliferators-activated receptors (PPARs). In fish, with the exception of PPARs, these proteins and their genes have not been much studied. However the availability of genomic sequences from fish at least will make it possible to identify homologues of these important genes in fish.

\section{Peroxisome Proliferator-Activated Receptors.}

Since their initial discovery as transcription factors which were activated by a variety of chemical and pharmacological compounds known to induce peroxisome proliferation in rodents (Issemann and Green, 1990), PPARs have been intensively studied in humans and rodents and have been the subject of several detailed reviews (eg (Desvergne et al. 2004; Hihi et al. 2002). PPARs are ligand-activated nuclear hormone receptors which act as heterodimers with retinoid X receptors (RXR). PPAR/RXR heterodimers bind to DNA sequences consisting of a consensus direct repeat of AGGTCA separated by 1 base pair (DR1 sequence). The PPAR/RXR heterodimer is a "permissive" complex in that it can be activated either by PPAR ligands or by RXR ligands. In mammals three genes encode PPARs; PPAR $\alpha$, PPAR $\beta$ (or $\delta$ ) and PPAR $\gamma$. These genes have distinct tissue expression profiles, which along with the tissue specific expression of corepressor and coactivator proteins, and differences in ligand selectivity, determine their roles in regulating genes involved in fatty acid homeostasis (Desvergne et al. 2006). The endogenous ligands of PPARs have not yet been unambiguously identified. All mammalian PPARs bind and are activated by unsaturated fatty acids, although a variety of oxidised derivatives of fatty acids, for example eicosanoids, have higher affinity and are more subtype specific. This has led to the view that PPARs are general fatty acid sensors, responding to increased cellular fatty acid levels or their metabolites which arise as a result of changes in nutritional status and energy metabolism (Michalik et al. 2006). Due to their important functions in fatty acid metabolism, PPARs have also been the subject of several studies in fish including Atlantic salmon and sea bream.

\section{PPAR $\alpha$}

In mammals a single gene for PPAR $\alpha$ encodes a transcription factor which is predominantly expressed in highly oxidative tissues such as liver and heart (Escher et al. 2001). Activating ligands for this receptor include fatty acids and some of their eicosanoid metabolites as well a variety of synthetic compounds (Desvergne and Wahli, 1999). Mice lacking PPAR $\alpha$ are unable to up-regulate hepatic $\beta$-oxidation in response to starvation develop fatty liver and also show cardiac metabolic defects (Leone et al. 1999). A number of studies (reviewed in Mandard et al. 2004) have demonstrated that PPAR $\alpha$ regulates genes involved in fatty acid oxidation, amino acid metabolism and glucose homeostasis. Thus, the ability of PPAR $\alpha$ to increase fatty acid $\beta$-oxidation is of considerable interest in aquaculture where fish are fed high fat diets in an effort to maximise the energy that can be supplied by dietary lipid, and so "spare" dietary protein for the synthesis of new tissue/flesh (Sargent and Tacon, 1999). PPAR $\alpha$ subtype cDNAs 
have been characterized from sea bream, sea bass and plaice (Pleuronectes platessa) (Boukouvala et al. 2004; Leaver et al. 2005). These proteins bear high identity to mammalian PPAR $\alpha$ and for reasons discussed below have been termed PPAR $\alpha 2$. Cellular transfection experiments have established that these fish PPAR $\alpha 2$ subtypes are activated by unsaturated fatty acids, and also by the mammalian PPAR $\alpha$-specific ligand Wy-14643. Furthermore, in sea bream and plaice, PPAR $\alpha 2$ mRNA is most highly expressed in liver and heart indicating that PPAR $\alpha 2$ is structurally and functionally homologous to mammalian PPAR $\alpha$. However searches of the genome data for pufferfish and zebrafish indicate that a further gene with a close phylogenetic relationship to PPAR $\alpha$ is present in these fish genomes (Maglich et al. 2003; Leaver et al. 2005). The functional characteristics of this subtype are presently unknown, but interestingly a PPAR $\alpha$ cDNA from Atlantic salmon (M. J. Leaver, unpublished) is clearly a homologue of the second uncharacterized gene from pufferfish, stickleback and medaka (Fig 4.) and has been termed PPAR $\alpha 1$. At present it is not known whether Atlantic salmon possess both PPAR $\alpha$ subtypes but, from the phylogenetic evidence, it seems likely that they do. The presence of PPAR $\alpha 1$ has also been recently confirmed in sea bream and sea bass (M. J. Leaver, G. Krey, unpublished). Since Ostariophysi (zebrafish), various Acanthopterygii (sea bream, sea bass, plaice, pufferfish, stickleback and medaka) and probably salmonids all possess two conserved PPAR $\alpha$ subtypes it is probable that all of the major bony fish clades are similarly endowed (Fig 4). This would indicate that PPAR $\alpha 1$ has a specific function in fish distinct from that of PPAR $\alpha 2$ and by extension mammalian PPAR $\alpha$. However, the functional characterization of this isoform is essential in order to fully address this hypothesis.

Compounds which activate PPAR $\alpha$ and increase $\beta$-oxidation in mammals have been tested in fish. The activity of ACO in Atlantic salmon hepatocytes is only mildly increased after fibrate treatment (Ruyter et al. 1997). Similarly the expression of ACO in Atlantic salmon liver and muscle is not affected by dietary tetradecylthioacetic acid (TTA; Kleveland et al. 2006a) which is in contrast to findings in rats (Froyland et al. 1996), where these compounds dramatically increase ACO via activation of PPAR $\alpha$. However, in Atlantic salmon, hepatic mitochondrial $\beta$-oxidation is significantly increased by dietary TTA whereas ACO activity is unaffected (Moya-Falcon et al. 2006). In contrast, rainbow trout treated with fenofibrate (a potent mammalian PPAR $\alpha$ agonist) show increased hepatic ACO activity and peroxisomal $\beta$-oxidation, whereas mitochondrial $\beta$-oxidation and CPT1 activity remain unchanged (Du et al. 2004). Thus, it is unclear whether these compounds have significant effects in salmonids. It should be noted that, although they have PPAR $\alpha$-mediated effects in rodents, these compounds have not yet been tested as direct activators of piscine PPARs. Nevertheless, in sea bream and plaice conjugated linoleic acid (CLA) is one of the most effective fatty acid activators of PPAR $\alpha 2$ in cellular transfection assays. Feeding of CLA to Atlantic salmon increases hepatic $\beta$-oxidation (Leaver et al. 2006) and CLA feeding increases ACO activity in sea bream. (Diez et al. 2007). Finally, it is of interest that the expression of PPAR $\alpha 2$ in the liver of sea bream appears to be dependent on the nutritional status of the fish, in a manner highly similar to that of mammalian PPAR $\alpha$. Thus, PPAR $\alpha 2$ liver mRNA expression is increased by fasting and decreased by feeding (Leaver et al. 2005). 
This effect appears to be liver-specific, as it has not been observed in the muscle, intestine, adipose, or heart tissues of sea bream (Diez et al. 2007).

\section{$P P A R \beta$}

Mammals have a single gene encoding PPAR $\beta$ and various studies suggest that it has a role in global control of lipid homeostasis. It is moderately activated by a range of unsaturated fatty acids (Forman et al. 1997) and has a broad tissue expression profile (Escher et al. 2001). PPAR $\beta$-deficient mice show reduced adipose stores (Peters et al. 2000) and treatment with synthetic ligands has demonstrated that PPAR $\beta$ directly controls lipid utilisation through up-regulation of genes involved in $\beta$-oxidation and energy uncoupling in various tissues (Dressel et al. 2003; Tachibana et al. 2005). In addition to functioning as a regulator of energy metabolism PPAR $\beta$ has also been shown to have significant roles in the control of cellular proliferation and differentiation (Burdick et al. 2006). PCR-amplified products of partial nuclear hormone receptor genes from zebrafish and Atlantic salmon suggest that more than one gene for PPAR $\beta$ may be present in fish (Robinson-Rechavi et al. 2001) and examination of the zebrafish genome database indicated that there are two PPAR $\beta$ genes in this Cypriniform (Leaver et al. 2005). However the subsequent generation and characterization of full length PPAR $\beta$ cDNAs from the Acanthopterygii, sea bream and plaice, indicate that these species contain a single PPAR $\beta$ gene. Furthermore, information from the pufferfish, stickleback and medaka (also Acanthopterygia) genome sequencing projects show that these fish also possess a single PPAR $\beta$ gene (Fig 4). In plaice, sea bream and sea bass the single PPAR $\beta$ gene shares many of the characteristics of its mammalian counterpart, having a broad tissue expression profile and being activated by unsaturated fatty acids (Leaver et al. 2005; Boukouvala et al. 2004).

In contrast to both cyprinids and Acanthopterygia, genomic screening of Atlantic salmon revealed the presence of four PPAR $\beta$ genes. (Leaver et al. 2007). These genes phylogenetically cluster as two families, termed ssPPAR $\beta 1$ and ssPPAR $\beta 2$, each containing two very similar genes (Fig. 4). The explanation for these differences in gene number in different fish is probably provided by the hypothesis that early in bony fish evolution a duplication of the ancestral genome took place (Meyer and Van De Peer, 2005). As different lineages of fish diverged these genes were either retained (e.g. the two PPAR $\beta$ subtypes in zebrafish) or lost (e.g. the single PPAR $\beta$ in pufferfish and all other Acanthopterygii so far studied) as has been demonstrated by genome comparisons (Woods et al. 2005). Atlantic salmon and other salmonids have undergone a further more recent genome duplication (Allendorf and Thorgaard, 1984) and this has resulted in the further duplication of two PPAR $\beta$ genes, derived from the early fish genome duplication. Recent functional studies of the Atlantic salmon PPAR $\beta$ genes shows that two of these subtypes have diverged functionally. Thus, ssPPAR $\beta 1 A$, bears all of the characteristics of other PPAR $\beta$ subtypes from mammals and fish, being activated by unsaturated fatty acids and being strongly activated by the mammalian PPAR $\beta$-specific ligand GW501506. In contrast the other Atlantic salmon PPAR $\beta$ subtype, ssPPAR $\beta 2 A$, is not activated by either fatty acids or synthetic ligands and moreover exerts a strong repression on the transcriptional activity of ssPPAR $\beta 1 \mathrm{~A}$. Whether ssPPAR $\beta 2 \mathrm{~A}$ is activated by another as 
yet undiscovered ligand and whether it exerts transcriptional repression on other PPARs or nuclear hormone receptors in general is not yet known. ssPPAR $\beta 1 \mathrm{~A}$ and $\beta 2 \mathrm{~A}$ are also differentially expressed, with $\beta 1 \mathrm{~A}$ predominating in liver and $\beta 2 \mathrm{~A}$ in gill (Leaver et al. 2007), which, given the potential for transcriptional repression and the possibility of nutritional regulation as observed in sea bream, would lead to considerably more complexity in PPAR signaling in salmonids than in the Acanthopterygii or in mammals.

\section{$P P A R \gamma$}

PPAR $\gamma$ is encoded by a single gene in mammals which, through alternative splicing, gives rise to two proteins, PPAR $\gamma 1$ and PPAR $\gamma 2$, with distinct N-terminal sequence (Tontonoz et al. 1994). PPAR $\gamma 2$ is highly expressed in adipose tissue whereas PPAR $\gamma 1$ is expressed to a high level in gut and at a much lower level in a variety of other tissues (Escher et al. 2001). Mammalian PPAR $\gamma$ is essential for fat accumulation particularly in adipocytes, but also in lipid-accumulating macrophages (Rosen et al. 1999; Fajas et al. 2001).

PPAR $\gamma$ was the first PPAR subype to be identified in fish, with cDNAs characterised from Atlantic salmon and plaice (Ruyter et al. 1997; Leaver et al. 1998). Subsequently the availability of genome information for zebrafish, stickleback, medaka and pufferfish has shown that, as in mammals, these fish possess a single PPAR $\gamma$ gene and studies on sea bream, sea bass and plaice also indicate the presence of a single gene (Fig 4; (Maglich et al. 2003; Boukouvala et al. 2004; Leaver et al. 2005). There are no indications yet of alternatively spliced products and thus alternative PPAR $\gamma$ proteins in fish. So far transcriptional activity has not been demonstrated for any fish PPAR $\gamma$. Both fatty acids and mammalian PPAR $\gamma$-specific ligands fail to activate sea bream or plaice PPAR $\gamma$ (Leaver et al. 2005) and similarly Atlantic salmon PPAR $\gamma$ is unresponsive to typical mammalian PPAR $\gamma$ agonists (Leaver et al., unpublished). Although fish PPAR $\gamma$ is clearly a homologue of mammalian PPAR $\gamma$, all piscine PPAR $\gamma$ proteins so far identified have a critical amino acid substitution, where a tyrosine residue conserved in all mammalian PPARs and essential for binding the carboxylic head group of fatty acids and synthetic ligands, is substituted for a methonine. This is suggested to abolish the ability of fatty acids and synthetic ligands to activate piscine PPAR $\gamma$ (Leaver et al. 2005; Maglich et al. 2003). Thus it is likely that piscine PPAR $\gamma$ is activated by as yet unidentified compounds, although given the overall similarity in structure to mammalian PPAR $\gamma$, these unidentified compounds are likely to be related to fatty acids. Differences between mammalian and piscine PPAR $\gamma$ are also evident from tissue expression profiles. PPAR $\gamma$ is expressed at a high level relative to other PPARs and in comparison to mammalian PPAR $\gamma$ in a wide range of sea bream and plaice tissues (Leaver et al. 2005). Furthermore, the expression of sea bream hepatic PPAR $\gamma$ mRNA levels increase upon feeding, whilst in adipose tissue they remain unchanged. In mammals feeding induces an increase in adipose PPAR $\gamma$ expression. Taken together the studies on piscine PPAR $\gamma$ suggest that, although a sequence homologue of mammalian PPAR $\gamma$, it has diverged functionally. Given the critical role of mammalian PPAR $\gamma$ in fat accumulation, it is 


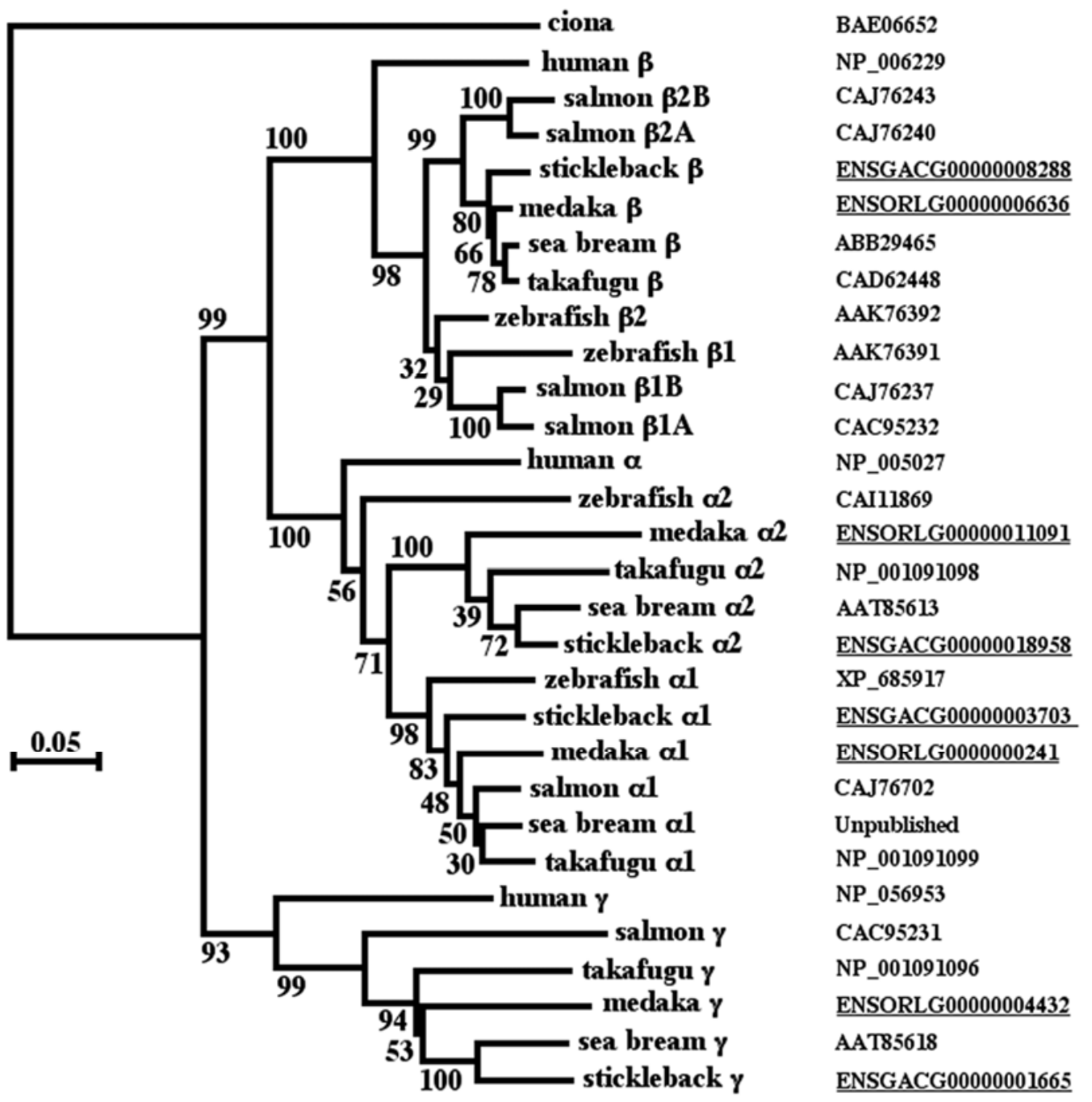

Figure 4. Molecular phylogeny of the ligand binding domains of PPARs.

PPAR sequences were obtained from the NCBI/EMBL databases or were derived from genomic sequence information by searching (TBLASTN) with human PPAR $\beta$ protein sequence. All sequences were aligned and neighbour joining trees derived and bootstrapped using ClustalX. Resulting unrooted trees were plotted with NJplot. The tree was rooted to the most similar nuclear receptor from the ascidian Ciona intestinalis. Numbers at nodes indicate the percentage frequency with which the tree topology was returned after bootstrapping the multiple alignment data through 1000 iterations. NCBI/EMBL protein sequence accession numbers are shown in normal text. ENSEMBL (www.ensembl.org) gene identification numbers are shown in italics for protein sequences derived from sequenced fish genomes. The accession number for an assembly of various salmon EST sequences from www.tigr.org is double underlined.

pertinent to ask the question whether the process of fat accumulation in fish might differ substantially from that in mammals. The identification of agonists for piscine PPAR $\gamma$ is a necessary step for further studies.

\section{Other Fatty Acid-Activated Transcription Factors}

In addition to PPARs a number of other transcription factors are activated by fatty acids (Clarke, 2004). Furthermore there are complex interactions among nuclear hormone 
receptors which are activated by cholesterol metabolites and bile acids (eg LXR and FXR) and those activated by fatty acids and their metabolites, such as PPARs (Desvergne et al. 2006). Other transcription factors directly activated by fatty acids include the Sterol Regulatory Element Binding Proteins (SREBPs) which are encoded by two genes, SREBP1 and SREBP2, in humans and other mammals. SREBP2 responds to membrane cholesterol levels and is activated when cellular cholesterol is low (Mcpherson and Gauthier, 2004). Its predominant function is the regulation of genes of the cholesterol biosynthesis pathway (Caballero et al. 2002; Maxwell et al. 2003). The SREBP1 gene gives rise to two proteins, SREBP1a and SREBP1c, by alternative splicing. SREBP1c is also responsive to reduced cholesterol and predominantly up-regulates the genes of the HUFA biosynthetic pathway, including fatty acyl $\Delta 5$ and $\Delta 6$ deaturases and fatty acyl elongases (Caballero et al. 2002). Increased cellular PUFA levels decrease the activity of SREBP1c by mechanisms which are not yet understood (Chen et al. 2004; Mcpherson and Gauthier, 2004). There are no studies yet of SREBPs in fish despite their importance in the regulation of HUFA biosynthesis.

Hepatic nuclear factor 4 (HNF4) proteins are transcription factors belonging to the nuclear receptor hormone superfamily. They are encoded by two distinct genes in mammals, termed HNF4 $\alpha$ and HNF4 $\gamma$ in humans, with a broad and overlapping tissue distribution (Drewes et al. 1996). HNF4 functions as a homodimer and binds to a DR1 repeat (Jiang et al. 1995) which shares a minimal consensus sequence with the elements bound by PPAR/RXR heterodimers, suggesting at least some degree of transcriptional cross-talk. Saturated and monounsaturated fatty acids between 14 and 18 carbons in length are bound tightly to both HNF4 $\alpha$ and HNF4 $\gamma$ when isolated from heterologous expression systems (Wisely et al. 2002). This is likely to occur in vivo where the presence of a permanently bound fatty acid is suggested to engender HNF4 with high constitutive activity (Dhe-Paganon et al. 2002). HNF4 $\alpha$ regulates a large and diverse array of genes in liver and in pancreas, including genes for fatty acid and glucose metabolism. Indeed $\mathrm{HNF} 4 \alpha$ may have a role in controlling up to $50 \%$ of the transcriptionally active genes in liver (Odom et al. 2004). Analysis of pufferfish genomes indicates that these species also possess two genes for HNF4 and these are homologous to human HNF4 $\alpha$ and HNF4 $\gamma$ (Maglich et al. 2003) and HNF4 regulates a major fraction of liver specific genes in zebrafish (Cheng et al. 2006) suggesting similar roles to those in mammals.

\section{ENDOCRINE CONTROL OF LIPID METABOLISM}

Lipid homeostasis is known to be regulated by a variety of interacting peptide hormones in fish. These hormones act at many different target tissues and may participate in protein, carbohydrate and lipid metabolism simultaneously. To cover all these aspects and hormones is beyond the scope of this review. Furthermore, it is clear that a comprehensive picture of the endocrine control of lipid homeostasis in fish is still lacking. Not only have important lipid-regulating hormones only recently been characterized in fish, but it is likely that there are important hormones yet to be identified. In addition, research during past decades on the endocrine control of lipid metabolism has been both sparse and fragmented and there is an obvious need to expand exploration of 
endocrine-nutritional interactions at the molecular level. The focus here will be on insulin and the recently discovered hormones ghrelin and leptin.

\section{Pancreatic hormones}

\section{Insulin}

Insulin has been identified in numerous fish (Conlon 2001), and often two insulin genes are present (Kavsan et al. 1993; Mommsen et al. 2001; Papasani et al. 2006). As in mammals, insulin has an anabolic action in fish, enhancing lipid storage by activating lipogenesis, and increasing protein synthesis and body growth (Nelson and Sheridan, 2006). Insulin receptors are present in several tissues, including adipose tissue (Navarro et al. 2002). In rainbow trout, insulin acts at several levels to promote lipid storage. Insulin affects the activity of the lipid mobilizing enzyme triacylglycerol lipase (TG lipase), by altering its state of phosphorylation (Plisetskaya, 1998; Harmon and Sheridan, 1992a; Harmon et al. 1993) et al. 1993). In addition, insulin stimulates adipose LPL activity in rainbow trout (Albalat et al. 2006). In vitro, insulin stimulates hepatic de novo lipid synthesis (Cowley and Sheridan, 1993), and inhibits adipocyte and hepatic lipolysis (Albalat et al. 2005b; Harmon and Sheridan, 1992a). In sea bream, on the other hand, insulin does not affect adipocyte lipolysis in vitro, except in fish fed a plant protein diet (Albalat et al. 2005a). Insulin may also modulate gene transcription as in Atlantic salmon hepatocytes where it upregulates mRNA levels of scavenger receptor class B, type I, which is important in mammalian lipid homeostasis (Kleveland et al. 2006b). Further, in red sea bream, the LPL gene contains a sequence homologous to the mammalian insulin responsive element (Oku et al. 2002) and insulin appears to induce adipocyte differentiation and increase differentiation-linked expression of the LPL gene in red sea bream (Oku et al. 2006). Nutritional status may influence the biological activity of insulin and hence link lipid nutrition to metabolism in rainbow trout, as plasma insulin levels decrease during fasting and postprandially along with a decreased number of insulin receptors in adipose tissue (Planas et al. 2000). Glucose injections stimulate lipolysis in rainbow trout, which is associated with a decrease in plasma insulin levels and an increase in TG lipase activity and elevated plasma fatty acid levels (Harmon et al. 1991; Harmon and Sheridan, 1992b).

\section{Glucagon}

Glucagon belongs to the secretin hormone family, which includes a number of other hormones having a vast array of metabolic affects. The glucagon gene encodes for several peptides that are expressed in different tissues (Nelson and Sheridan, 2006). Glucagon is lipolytic and stimulates hepatic TG lipase activity in rainbow trout and coho salmon (Harmon and Sheridan, 1992a; Plisetskaya et al. 1989). Glucagon also stimulates TG lipase activity in adipocytes in sea bream and rainbow trout (Albalat et al. 2005a; Albalat et al. 2005b). However, further studies are needed to understand the molecular mechanisms of glugon action in fish.

\section{Ghrelin}


Ghrelin was identified as a growth hormone (GH) secretogogue in 1999 using the "orphan receptor strategy" and the fact that a number of G-protein coupled receptors had been found in the genomes of mammals and fish. The receptors were expressed in cultured cells and their activation monitored by changes in second messenger systems. This functional genomics approach was further used to investigate the physiological function of ghrelin and its receptor, called the $\mathrm{GH}$ secretogogue receptor or the ghrelin receptor (Kojima and Kangawa, 2005). The hormone has now been cloned in several fish, including rainbow trout and sea bream (Kaiya et al. 2003; Yeung et al. 2006; Kojima and Kangawa, 2005; Kangawa, 2005). In these two species, mature ghrelin ranges from 20 to 24 amino acids and it has a unique fatty acid modification on the third amino acid, common to all species, which is necessary for its biological activity (Kojima and Kangawa, 2005). Ghrelin is expressed only in stomach of sea bream, whereas in rainbow trout, relatively high expression is also found in brain, hypothalamus and intestine (Kaiya et al. 2003; Yeung et al. 2006). The genomic organization of rainbow trout ghrelin differs from other fish, and is more similar to the mouse ghrelin gene (Kojima and Kangawa, 2005). Functional analysis of the sea bream ghrelin gene indicates that several factors in the regulation of ghrelin transcription differ from mammals, e.g. candidate transcription factor-binding sites (Yeung et al. 2006). Two cDNA transcripts, primarily expressed in the pituitary and central nervous system for a single ghrelin receptor gene have also been reported for black sea bream (Chan and Cheng, 2004). Chronic ghrelin treatment stimulates food intake and increased liver and muscle fat deposition in tilapia and rainbow trout (Riley et al. 2005; Shepherd et al. 2007). However, the effect of conspecific ghrelin on salmon or sea bream food intake and lipid metabolism is not yet known. Ghrelin clearly has several mechanisms of action to promote lipid storage in rodents, e.g. by increasing food intake while decreasing fat utilization (Tschop et al. 2000), and increasing the transcription of various lipogenic enzymes in white adipose tissue (Barazzoni et al. 2005). It also stimulates preadipocyte differentiation and upregulates the expression of PPAR- $\gamma 2$ during this process (Choi et al. 2003). There is circumstantial evidence that ghrelin is involved in energy storage in rainbow trout; plasma ghrelin levels are positively correlated to condition factor, liver and muscle lipid content, and suppressed during long-term fasting (Jönsson et al. 2007). This is opposite to results from mammals (Kojima and Kangawa, 2005), indicating that there may be species-differences in ghrelin function. Given that ghrelin stimulates GH secretion, and that $\mathrm{GH}$ is a lipolytic hormone, understanding the interaction between the GH-IGF-I system and ghrelin in regulating growth and adiposity represents a challenge. Interestingly, the recently discovered hormone obestatin which decreased food intake in rats, is derived from the ghrelin gene through post-translational modifications (Zhang et al 2005). The sea bream ghrelin gene shows a region with low similarity to mammalian obestatin (Yeung et al. 2006), and it remains to be investigated whether this represents an orthologue of mammalian obestatin.

\section{Leptin}

Through advances in mammalian research, it is clear that adipose tissue is not only a passive fat storage site, but a highly active secretor of numerous peptide hormones 
and cytokines, which act at various sites to regulate energy homeostasis (Ahima, 2006). The most well studied of these is the $o b$ gene product leptin, the discovery of which was a scientific breakthrough in the understanding of how body weight is regulated in mammals (Zhang et al. 1994). Leptin is a peptide hormone belonging to the class-I helical cytokines. It is produced predominantly in adipose tissue, and circulates in proportion to body mass in mammals, functioning as a negative feedback signal which regulates fat stores. Cytokines are not well conserved between phyla and the identification of fish homologues or orthologues of important cytokines has proved difficult, as for fish leptin (Huising et al. 2006b). Leptin-like immunoreactivity in fish has been reported, but the validity of using heterologous mammalian antibodies in these assays has been questioned (Johnson et al. 2000). However, as the gene structure of orthologous cytokines is well conserved, the availability of genome sequences for pufferfish and zebrafish enabled the search for candidate piscine cytokine genes by concentrating searches in areas of the genome flanked by genes which are clearly conserved, at the sequence and positional level in mammals. This genomic synteny approach resulted in the identification of leptin genes in pufferfish (Takifugu rubripes) and common carp (Kurokawa et al. 2005; Huising et al. 2006a). Unlike in mammals, leptin appears to be mostly expressed in the liver of these two species. Leptin-like genes for pufferfish, medaka and Atlantic salmon were found through further database searches (Kurokawa et al. 2005), and the lepin gene for rainbow trout has been added to GeneBank (Accession number AM042713.1). Future studies will reveal if there are general species differences in the tissue expression of leptin in fish.

In mammals, leptin acts on the central nervous system, decreasing food intake, and activating sympathetic activity to increase energy expenditure through thermogenesis and elevated fatty acid oxidation, which results in weight loss. However, due to the recent discovery of leptin in fish, physiological studies using homologous hormones are still lacking and available data on leptin action in fish are based on the use of mammalian leptin. Leptin treatment of salmonids revealed no clear physiological effects (Baker et al. 2000), but in goldfish, it suppressed food intake (Volkoff et al. 2003; De Pedro et al. 2006). Chronic leptin treatment decreased appetite as well as liver lipid content in goldfish, with concomitant elevation of hepatic and muscle glycogen stores (De Pedro et al. 2006). Due to the exceptionally low sequence similarity between fish and mammalian leptins, these data must be interpreted with caution and repeated with conspecific fish leptin. In common carp, there is a postprandial increase in leptin mRNA expression, but no long-term effects of fasting on leptin mRNA expression was observed despite clear effects on body weight and metabolism (Huising et al. 2006a). Data indicate that plasma leptin levels may be positively correlated with plasma $\mathrm{PGE}_{2}$ levels, but a human leptin immoassay kit was used (Richard et al. 2006). Hopefully, conspecific tools will be established in the near future, enabling more relevant research on leptin function in fish.

\section{Other hormones}

With lipid metabolism being of central importance for energy balance and general physiology of fish as in other vertebrates, hormones involved in the regulation of various life processes are likely to affect lipid homeostasis, directly or indirectly. These include neuropeptides involved in regulation of feed intake and appetite, such as corticotrophin- 
releasing factor (CRF), bombesin, cholecystokinin (CCK), galanin, opiod peptides and neuropeptide Y (for review, see De Pedro and Björnsson, 2001). Also, hormones regulating appetite, growth and metabolism, in particular, growth hormone $(\mathrm{GH})$, insulinlike growth factor I (IGF-I) and somatostatin may have indirect effects on lipid homeostasis, in addition to the direct lipolytic effects of GH on the liver in salmonids (for review see, (Bjornsson, 1997; Bjornsson et al. 2002; Perez-Sanchez et al. 2002). Stressrelated hormones such as catecholamines and corticosteroids affect energy balance including lipid stores (for review see (Wendelaar Bonga, 1997). Puberty and sexual maturation represents a life stage transition where significant amounts of lipids are needed for gonadal maturation, as well as for the physical activity, including migration, related to spawning. Thus, not only may reproductive hormones affect lipid stores indirectly, but lipid stores have long been hypothesized to be of major importance for triggering life stage transitions such as puberty, as well as smoltification of salmonids (Shearer and Swanson, 2000; Morgan et al. 2002). The pituitary hormone somatolactin, exclusive to fish, has been suggested to have a role in lipid metabolism (Company et al. 2001 ; De Celis et al. 2004 ; Fukada et al. 2005).

\section{CONCLUSIONS AND PERSPECTIVES}

Although there have been numerous studies on piscine lipid metabolism and on the expression and function of selected genes involved in lipid homeostasis, the results have been at times conflicting. Attention is seldom paid to the metabolic differences which exist between fish as well as postprandial effects or to developmental stage. Much of the difference among fish is doubtless a result of particular metabolic and life history adaptations to varied environments. For example, Atlantic salmon may have adapted to relatively nutrient poor riverine environments by subfunctionalization of multiple fatty acyl desaturase genes which originally arose as a result of a salmonid tetraploidization event. In contrast, it is likely that the marine sea bream and other marine species have a relative deficiency of HUFA biosynthetic machinery that makes these species dependent on nutrient rich marine food sources. These types of studies have direct relevance to the formulation of optimal diets for the domestication of fish in aquaculture. The availability of fish genome sequences are providing critical information to facilitate much of the research in this area, and the prospect of a salmonid genome sequence would further empower aquaculture researchers. A recent example is the in silico discovery of the fish leptin gene using the pufferfish genome and such approaches will prove valuable for further identification and characterization of novel fish hormones. In the immediate future, the main challenges are to integrate the available genomic data with physiological studies on fish and to access powerful genetic manipulation technologies available for the model species zebrafish and medaka. However, given what we already know of the diversity of gene numbers and physiological responses in different fish, there is a strong argument for choosing model species with care. For example the use of medaka to address problems or hypotheses in relating to the nutrition of the marine Acanthoptergii, (eg sea bass or sea bream) would be preferable to using the more distantly related zebrafish. A major objective will be the integration of data from model species with the effects of endocrine hormones, lipid metabolism and life history in commercial or environmentally relevant fish and the availability of high density cDNA microarrays for 
Atlantic salmon and for sea bream will provide platforms for undertaking this research. The outcomes of fish nutrigenomic research will not just be of relevance to aquaculture but will also enable the identification of differences underlying vertebrate physiologies. These outcomes will elucidate species-specific adaptations to environmental conditions, and have the potential to inform and stimulate research in many biological disciplines, from ecology to human health.

\section{ACKNOWLEDGEMENTS}

This review summarizes the results of studies largely funded by the Commission of the European Communities.and has been carried out within the project "AQUAFUNC" (EU-SSA-022685) with financial support from the Commission of the European Communities.

\section{REFERENCES}

Agaba, M., Tocher, D.R., Dickson, C.A., Dick, J.R. and Teale, A.J. Zebrafish cDNA encoding multifunctional fatty acid elongase involved in production of eicosapentaenoic (20:5n-3) and docosahexaenoic (22:6n-3) acids. Marine Biotechnology 6, 251-261 (2004) .

Agaba, M.K., Tocher, D.R., Zheng, X.Z., Dickson, C.A., Dick, J.R. and Teale, A.J. Cloning and functional characterisation of polyunsaturated fatty acid elongases of marine and freshwater teleost fish. Comparative Biochemistry and Physiology BBiochemistry \& Molecular Biology 142, 342-352 (2005) .

Ahima, R.S. Adipose tissue as an endocrine organ. Obesity 14, 242-249 (2006).

Albalat, A., Gomez-Requeni, P., Rojas, P., Medale, F., Kaushik, S., Vianen, G.J., Van Den Thillart, G., Gutierrez, J., Perez-Sanchez, J. and Navarro, I. Nutritional and hormonal control of lipolysis in isolated gilthead seabream (Sparus aurata) adipocytes. American Journal of Physiology-Regulatory Integrative and Comparative Physiology 289, R259-R265 (2005a).

Albalat, A., Gutierrez, J. and Navarro, I. Regulation of lipolysis in isolated adipocytes of rainbow trout (Oncorhynchus mykiss): the role of insulin and glucagon. Comparative Biochemistry and Physiology a-Molecular \& Integrative Physiology 142, 347-354 (2005b).

Albalat, A., Sanchez-Gurmaches, J., Gutierrez, J. and Navarro, I. Regulation of lipoprotein lipase activity in rainbow trout (Oncorhynchus mykiss) tissues. General and Comparative Endocrinology 146, 226-235 (2006).

Allendorf, F.W. and Thorgaard, G.H. Tetraploidy and the evolution of salmonid fishes. In Evolutionary genetics of salmonid fishes. Eds. Turner, B.J., New York, Plenum Press pp. 1-53 (1984).

Alvarez, M.J., Diez, A., Lopez-Bote, C., Gallego, M. and Bautista, J.M. Short-term modulation of lipogenesis by macronutrients in rainbow trout (Oncorhynchus mykiss) hepatocytes. British Journal of Nutrition 84, 619-628 (2000).

Baker, D.M., Larsen, D.A., Swanson, P. and Dickhoff, W.W. Long-term peripheral treatment of immature coho salmon (Oncorhynchus kisutch) with human leptin has no clear physiologic effect. General and Comparative Endocrinology 118, 134-138 (2000). 
Barazzoni, R., Bosutti, A., Stebel, M., Cattin, M.R., Roder, E., Visintin, L., Cattin, L., Biolo, G., Zanetti, M. and Guarnieri, G. Ghrelin regulates mitochondrial-lipid metabolism gene expression and tissue fat distribution in liver and skeletal muscle. American Journal of Physiology-Endocrinology and Metabolism 288, E228-E235 (2005).

Bezard, J., Blond, J.P., Bernard, A. and Clouet, P. The metabolism and availability of essential fatty-acids in animal and human tissues. Reproduction Nutrition Development 34, 539-568 (1994).

Bjornsson, B.T. The biology of salmon growth hormone: from daylight to dominance. Fish Physiology and Biochemistry 17, 9-24 (1997).

Bjornsson, B.T., Johansson, V., Benedet, S., Einarsdottir, I.E., Hildahl, J., Agustsson, T. and Jonsson, E. Growth hormone endocrinology of salmonids: regulatory mechanisms and mode of action. Fish Physiology and Biochemistry 27, 227-242 (2002).

Boukouvala, E., Antonopoulou, E., Favre-Krey, L., Diez, A., Bautista, J.M., Leaver, M.J., Tocher, D.R. and Krey, G. Molecular characterization of three peroxisome proliferator-activated receptors from the sea bass (Dicentrarchus labrax). Lipids 39, 1085-1092 (2004).

Brandt, J.M., Djouadi, F. and Kelly, D.P. Fatty acids activate transcription of the muscle carnitine palmitoyltransferase i gene in cardiac myocytes via the peroxisome proliferator-activated receptor alpha. Journal of Biological Chemistry 273, 2378623792 (1998).

Bremer, J. The role of carnitine in cell metabolism. In Carnitine Today. Eds: De Simine, C. Famularo, G. Landes Bioscience, Austin 1-38 (1997).

Burdick, A.D., Kim, D.J., Peraza, M.A., Gonzalez, F.J. and Peters, J.M. The role of peroxisome proliferator-activated receptor-beta/delta in epithelial cell growth and differentiation. Cellular Signalling 18, 9-20 (2006).

Caballero, M.J., Obach, A., Rosenlund, G., Montero, D., Gisvold, M. and Izquierdo, M.S. Impact of different dietary lipid sources on growth, lipid digestibility, tissue fatty acid composition and histology of rainbow trout, Oncorhynchus mykiss. Aquaculture 214, 253-271 (2002).

Chan, C.B. and Cheng, C.H.K. Identification and functional characterization of two alternatively spliced growth hormone secretagogue receptor transcripts from the pituitary of black seabream Acanthopagrus schlegeli. Molecular and Cellular Endocrinology 214, 81-95 (2004).

Chen, G.X., Liang, G.S., Ou, J.F., Goldstein, J.L. and Brown, M.S. Central role for liver $\mathrm{x}$ receptor in insulin-mediated activation of SREBP-1c transcription and stimulation of fatty acid synthesis in liver. Proceedings of the National Academy of Sciences of the United States of America 101, 11245-11250 (2004).

Cheng, W., Guo, L., Zhang, Z.H., Soo, H.M., Wen, C.M., Wu, W. and Peng, J.R. HNF factors form a network to regulate liver-enriched genes in zebrafish. Developmental Biology 294, 482-496 (2006).

Choi, K.C., Roh, S.G., Hong, Y.H., Shrestha, Y.B., Hishikawa, D., Chen, C., Kojima, M., Kangawa, K. and Sasaki, S.I. The role of ghrelin and growth hormone secretagroogues receptor on rat adipogenesis. Endocrinology 144, 754-759 (2003). 
Clarke, S.D. The multi-dimensional regulation of gene expression by fatty acids: polyunsaturated fats as nutrient sensors. Current Opinion in Lipidology 15, 13-18 (2004).

Coe, N.R. and Bernlohr, D.A. Physiological properties and functions of intracellular fatty acid-binding proteins. Biochimica Et Biophysica Acta-Lipids and Lipid Metabolism 1391, 287-306 (1998).

Company, R., Astola, A., Pendon, C., Valdivia, M.M. and Perez-Sanchez, J. Somatotropic regulation of fish growth and adiposity: growth hormone $(\mathrm{GH})$ and somatolactin (SL) relationship. Comparative Biochemistry and Physiology CToxicology \& Pharmacology 130, 435-445 (2001).

Company, R., Calduch-Giner, J.A., Kaushik, S. and Perez-Sanchez, J. Growth performance and adiposity in gilthead sea bream (Sparus aurata): risks and benefits of high energy diets. Aquaculture 171, 279-292 (1999).

Cook, H.W. Fatty acid desaturation and chain elongation in eukaryotes. In Biochemistry of Lipids; Lipoproteins and Membranes. Eds Vance, D.E. and Vance, J.E. Elevier, Amsterdam 129-152 (1996).

Cowey, C.B. and Cho, C.Y. Nutritional-requirements of fish. Proceedings of the Nutrition Society 52, 417-426 (1993).

Cowey, C.B. and Walton, M.J. Intermediary Metabolism. In: J.E. Halver, Editor, Fish Nutrition (2nd edn), Academic Press, New York 259-329 (1989).

Cowley, D.J. and Sheridan, M.A. Insulin stimulates hepatic lipogenesis in rainbow trout, Oncorhynchus mykiss. Fish Physiology and Biochemistry 11, 421-428 (1993).

Crockett, E.L. and Sidell, B.D. Peroxisomal -oxidation is a significant pathway for catabolism of fatty-acids in a marine teleost. American Journal of Physiology 264, R1004-R1009 (1993).

De Celis, S.V.R., Gomez, P., Calduch-Giner, J.A., Medale, F. and Perez-Sanchez, J. Expression and characterization of european sea bass (Dicentrarchus labrax) somatolactin: assessment of in vivo metabolic effects. Marine Biotechnology 5, 92101 (2003).

De Celis, S.V.R., Rojas, P., Gomez-Requeni, P., Albalat, A., Gutierrez, J., Medale, F., Kaushik, S.J., Navarro, I. and Perez-Sanchez, J. Nutritional assessment of somatolactin function in gilthead sea bream (Sparus aurata): concurrent changes in somatotropic axis and pancreatic hormones. Comparative Biochemistry and Physiology a-Molecular \& Integrative Physiology 138, 533-542 (2004).

De Pedro, N. and Björnsson, B.T. Regulation of food intake by neuropeptides and hormones. In: Houlihan, D., Boujard, T., Jobling, M. (Eds) Food intake in fish. Oxford Blackwell Science 269-296 (2001).

De Pedro, N., Martinez-Alvarez, R. and Delgado, M.J. Acute and chronic leptin reduces food intake and body weight in goldfish (Carassius auratus). Journal of Endocrinology 188, 513-520 (2006).

Desvergne, B., Michalik, L. and Wahli, W. Be fit or be sick: peroxisome proliferatoractivated receptors are down the road. Molecular Endocrinology 18, 1321-1332 (2004).

Desvergne, B. and Wahli, W. Peroxisome proliferator-activated receptors: nuclear control of metabolism. Endocrine Reviews 20, 649-688 (1999). 
Desvergne, B.A., Michalik, L. and Wahli, W. Transcriptional regulation of metabolism. Physiological Reviews 86, 465-514 (2006)

Dhe-Paganon, S., Duda, K., Iwamoto, M., Chi, Y.I. and Shoelson, S.E. Crystal structure of the HNF4 alpha ligand binding domain in complex with endogenous fatty acid ligand. Journal of Biological Chemistry 277, 37973-37976 (2002).

Diez, A., Menoyo, D., Pérez-Benavente, S., Calduch-Giner, J.A., Vega-Rubin de Celis, S., Obach, A., Favre-Krey, L., Boukouvala, E., Leaver, M.J., Tocher, D.R., PérezSanchez, J., Krey, G. and Bautista, J.M. Conjugated Linoleic Acid Affects Lipid Composition, Metabolism, and Gene Expression in Gilthead Sea Bream (Sparus aurata L). Journal of Nutrition 137, 1363-1369 (2007).

Donohue, M., Baldwin, L.A., Leonard, D.A., Kostecki, P.T. and Calabrese, E.J. Effect of hypolipidemic drugs gemfibrozil, ciprofibrate, and clofibric acid on peroxisomal oxidation in primary cultures of rainbow-trout hepatocytes. Ecotoxicology and Environmental Safety 26, 127-132 (1993).

Dressel, U., Allen, T.L., Pippal, J.B., Rohde, P.R., Lau, P. and Muscat, G.E.O. The peroxisome proliferator-activated receptor / agonist, GW501516, regulates the expression of genes involved in lipid catabolism and energy uncoupling in skeletal muscle cells. Molecular Endocrinology 17, 2477-2493 (2003).

Drewes, T., Senkel, S., Holewa, B. and Ryffel, G.U. Human hepatocyte nuclear factor 4 isoforms are encoded by distinct and differentially expressed genes. Molecular and Cellular Biology 16, 925-931 (1996) .

Du, Z.Y., Demizieux, L., Degrace, P., Gresti, J., Moindrot, B., Liu, Y.J., Tian, L.X., Cao, J.M. and Clouet, P. Alteration of $20: 5 n-3$ and $22: 6 n-3$ fat contents and liver peroxisomal activities in fenofibrate-treated rainbow trout. Lipids 39, 849-855 (2004).

Escher, P., Braissant, O., Basu-Modak, S., Michalik, L., Wahli, W. and Desvergne, B. Rat PPARs: quantitative analysis in adult rat tissues and regulation in fasting and refeeding. Endocrinology 142, 4195-4202 (2001).

Fajas, L., Debril, M.B. and Auwerx, J. Peroxisome proliferator-activated receptorgamma: from adipogenesis to carcinogenesis. Journal of Molecular Endocrinology 27, 1-9 (2001).

FAO The state of world fisheries and agriculture 2006. (www.fao.org/sof/sofia/index_en.html) 1-180 (2006).

Forman, B.M., Chen, J. and Evans, R.M. Hypolipidemic drugs, polyunsaturated fatty acids, and eicosanoids are ligands for peroxisome proliferator-activated receptors alpha and delta. Proceedings of the National Academy of Sciences of the United States of America 94, $4312-4317$ (1997).

Frohnert, B.I. and Bernlohr, D.A. Regulation of fatty acid transporters in mammalian cells. Progress in Lipid Research 39, 83-107 (2000).

Froyland, L., Helland, K., Totland, G.K., Kryvi, H. and Berge, R.K. A hypolipidemic peroxisome proliferating fatty acid induces polydispersity of rat liver mitochondria. Biology of the Cell 87, 105-112 (1996).

Froyland, L., Lie, O. and Berge, R.K. Mitochondrial and peroxisomal -oxidation capacities in various tissues from atlantic salmon Salmo salar. Aquaculture Nutrition 6, 85-89 (2000). 
Froyland, L., Madsen, L., Eckhoff, K.M., Lie, O. and Berge, R.K. Carnitine palmitoyltransferase I, carnitine palmitoyltransferase II, and acyl-CoA oxidase activities in atlantic salmon (Salmo salar). Lipids 33, 923-930 (1998).

Fukada, H., Ozaki, Y., Pierce, A.L., Adachi, S., Yamauchi, K., Hara, A., Swanson, P. and Dickhoff, W.W. Identification of the salmon somatolactin receptor, a new member of the cytokine receptor family. Endocrinology 146, 2354-2361 (2005).

Furuhashi, M., Ura, N., Murakami, H., Hyakukoku, M., Yamaguchi, K., Higashiura, K. and Shimamoto, K. Fenofibrate improves insulin sensitivity by reducing muscle lipid content via increase of fatty acid binding protein and -oxidation in muscle. Journal of Hypertension 20, S56 (2002).

Grove, T.J. and Sidell, B.D. Fatty acyl-CoA synthetase from Antarctic notothenioid fishes may influence substrate specificity of fat oxidation. Comparative Biochemistry and Physiology B-Biochemistry \& Molecular Biology 139, 53-63 (2004).

Gutieres, S., Damon, M., Panserat, S., Kaushik, S. and Medale, F. Cloning and tissue distribution of a carnitine palmitoyltransferase I gene in rainbow trout (Oncorhynchus mykiss). Comparative Biochemistry and Physiology B-Biochemistry \& Molecular Biology 135, 139-151 (2003).

Hamilton, J.A. Fatty acid transport: difficult or easy? Journal of Lipid Research 39, 467-481 (1998).

Harmon, J.S., Eilertson, C.D., Sheridan, M.A. and Plisetskaya, E.M. Insulin suppression is associated with hypersomatostatinemia and hyperglucagonemia in glucose-injected rainbow-trout. American Journal of Physiology 261, R609-R613 (1991).

Harmon, J.S., Rieniets, L.M. and Sheridan, M.A. Glucagon and insulin regulate lipolysis in trout liver by altering phosphorylation of triacylglycerol lipase. American Journal of Physiology 265, R255-R260 (1993).

Harmon, J.S. and Sheridan, M.A. Effects of nutritional state, insulin, and glucagon on lipid mobilization in rainbow-trout, Oncorhynchus mykiss. General and Comparative Endocrinology 87, 214-221 (1992a).

Harmon, J.S. and Sheridan, M.A. Glucose-stimulated lipolysis in rainbow-trout, Oncorhynchus mykiss, liver. Fish Physiology and Biochemistry 10, 189-199 (1992b). Hastings, N., Agaba, M., Tocher, D.R., Leaver, M.J., Dick, J.R., Sargent, J.R. and Teale, A.J. A vertebrate fatty acid desaturase with delta 5 and delta 6 activities. Proceedings of the National Academy of Sciences of the United States of America 98, 14304-14309 (2001).

Hastings, N., Agaba, M.K., Tocher, D.R., Zheng, X.Z., Dickson, C.A., Dick, J.R. and Teale, A.J. Molecular cloning and functional characterization of fatty acyl desaturase and elongase cDNAs involved in the production of eicosapentaenoic and docosahexaenoic acids from alpha-linolenic acid in atlantic salmon (Salmo salar). Marine Biotechnology 6, 463-474 (2004).

Hemre, G.I. and Sandnes, K. Effect of dietary lipid level on muscle composition in Atlantic salmon Salmo salar. Aquaculture Nutrition 5, 9-16 (1999).

Henderson, R.J. and Sargent, J.R. Lipid-metabolism in rainbow-trout (Salmo gairdnerii) fed diets containing partially hydrogenated fish oil. Comparative Biochemistry and Physiology B-Biochemistry \& Molecular Biology 78 , 557-564 (1984).

Henderson, R.J. and Tocher, D.R. The lipid-composition and biochemistry of fresh-water fish. Progress in Lipid Research 26, 281-347 (1987). 
Herrmann, T., Buchkremer, F., Gosch, I., Hall, A.M., Bernlohr, D.A. and Stremmel, W. Mouse fatty acid transport protein 4 (fatp4): characterization of the gene and functional assessment as a very long chain acyl-CoA synthetase. Gene 270, 31-40 (2001).

Hertzel, A.V. and Bernlohr, D.A. The mammalian fatty acid-binding protein multigene family: molecular and genetic insights into function. Trends in Endocrinology and Metabolism 11, 175-180 (2000).

Hihi, A.K., Michalik, L. and Wahli, W. PPARs: transcriptional effectors of fatty acids and their derivatives. Cellular and Molecular Life Sciences 59, 790-798 (2002).

Huising, M.O., Geven, E.J.W., Kruiswijk, C.P., Nabuurs, S.B., Stolte, E.H., Spanings, F.A.T., Verburg-Van Kemenade, B.M.L. and Flik, G. Increased leptin expression in common carp (Cyprinus carpio) after food intake but not after fasting or feeding to satiation. Endocrinology 147, 5786-5797 (2006a).

Huising, M.O., Kruiswijk, C.P. and Flik, G. Phylogeny and evolution of class-I helical cytokines. Journal of Endocrinology 189, 1-25 (2006b).

Inestrosa, N.C., Bronfman, M. and Leighton, F. Properties of fatty acyl-CoA oxidase from rat-liver, a peroxisomal flavoprotein. Life Sciences 25, 1127-1135 (1979).

Issemann, I. and Green, S. Activation of a member of the steroid-hormone receptor superfamily by peroxisome proliferators. Nature 347, 645-650 (1990).

Izquierdo, M.S., Obach, A., Arantzamendi, L., Montero, D., Robaina, L. and Rosenlund, G. Dietary lipid sources for seabream and seabass: growth performance, tissue composition and flesh quality. Aquaculture Nutrition 9, 397-407 (2003).

Jakobsson, A., Westerberg, R. and Jacobsson, A. Fatty acid elongases in mammals: their regulation and roles in metabolism. Progress in Lipid Research 45, 237-249 (2006).

Jiang, G.Q., Nepomuceno, L., Hopkins, K. and Sladek, F.M. Exclusive homodimerization of the orphan receptor hepatocyte nuclear factor-4 defines a new subclass of nuclear receptors. Molecular and Cellular Biology 15, 5131-5143 (1995).

Jobling, M. and Johansen, S.J.S. Fat distribution in Atlantic salmon Salmo salar L. In relation to body size and feeding regime. Aquaculture Research 34, 311-316 (2003).

Johnson, R.M., Johnson, T.M. and Londraville, R.L. Evidence for leptin expression in fishes. Journal of Experimental Zoology 286, 718-724 (2000).

Jordal, A.E.O., Hordvik, I., Pelsers, M., Bemlohr, D.A. and Torstensen, B.E. FABP3 and FABP10 in Atlantic salmon (Salmo salar L1.) - General effects of dietary fatty acid composition and life cycle variations. Comparative Biochemistry and Physiology BBiochemistry \& Molecular Biology 145, 147-158 (2006).

Jordal, A.E.O., Lie, O. and Torstensen, B.E. Complete Replacement of dietary fish oil with a vegetable oil blend effects liver and plasma lipoprotein levels in Atlantic Salmon (Salmo salar). Aquaculture Nutrition 13, 114-130 (2007).

Jordal, A.E.O., Torstensen, B.E., Tsoi, S., Tocher, D.R., Lall, S.P. and Douglas, S.E.

Dietary rapeseed oil affects the expression of genes involved in hepatic lipid metabolism in Atlantic salmon (Salmo salar L.). Jounal of Nutrition 135, 2355-2361 (2005).

Jump, D.B. Fatty acid regulation of gene transcription. Critical Reviews in Clinical Laboratory Sciences 41, 41-78 (2004).

Jönsson, E., Forsman, A., Einarsdottir, I.E., Kaiya, H., Ruohonen, K. and Björnsson, B.T. Plasma ghrelin levels in rainbow trout in response to fasting and food composition, 
and effects of ghrelin on voluntary food intake. Comparative Physiology and Biochemistry A 147, 1116-1124 (2007).

Kaiya, H., Kojima, M., Hosoda, H., Moriyama, S., Takahashi, A., Kawauchi, H. and Kangawa, K. Peptide purification, complementary deoxyribonucleic acid (DNA) and genomic DNA cloning, and functional characterization of ghrelin in rainbow trout. Endocrinology 144, 5215-5226 (2003).

Kangawa, K. Ghrelin: discovery and physiological significance. Journal of Pharmacological Sciences 97, 3P (2005).

Kavsan, V.M., Koval, A.P., Grebenjuk, V.A., Chan, S.J., Steiner, D.F., Roberts, C.T. and Leroith, D. Structure of the chum salmon insulin-like growth factor-I gene. DNA and Cell Biology 12, 729-737 (1993).

Kleveland, E.J., Ruyter, B., Vegusdal, A., Sundvold, H., Berge, R.K. and Gjoen, T. Effects of 3-thia fatty acids on expression of some lipid related genes in Atlantic salmon (Salmo salar L.). Comparative Biochemistry and Physiology B-Biochemistry \& Molecular Biology 145, 239-248 (2006a).

Kleveland, E.J., Syvertsen, B.L., Ruyter, B., Vegusdal, A., Jorgensen, S.M. and Gjoen, T. Characterization of scavenger receptor class b, type I in Atlantic salmon (Salmo salar L.). Lipids 41, 1017-1027 (2006b).

Kojima, M. and Kangawa, K. Ghrelin: structure and function. Physiological Reviews 85, 495-522 (2005).

Kurokawa, T., Uji, S. and Suzuki, T. Identification of cDNA coding for a homologue to mammalian leptin from pufferfish, Takifugu rubripes. Peptides 26, $745-750$ (2005).

Le, W.P., Abbas, A.S., Sprecher, H., Vockley, J. and Schulz, H. Long-chain acyl-CoA dehydrogenase is a key enzyme in the mitochondrial -oxidation of unsaturated fatty acids. Biochimica Et Biophysica Acta-Molecular and Cell Biology of Lipids 1485, 121-128 (2000).

Leaver, M.J., Boukouvala, E., Antonopoulou, E., Diez, A., Favre-Krey, L., Ezaz, M.T., Bautista, J.M., Tocher, D.R. and Krey, G. Three peroxisome proliferator-activated receptor isotypes from each of two species of marine fish. Endocrinology 146, 3150$3162(2005)$.

Leaver, M.J., Ezaz, M.T., Fontagne, S., Tocher, D.R., Boukouvala, E. and Krey, G. Multiple peroxisome proliferator-activated receptor . subtypes from Atlantic salmon (Salmo salar). Journal of Molecular Endocrinology 391-400 (2007).

Leaver, M.J., Tocher, D.R., Obach, A., Jensen, L., Henderson, R.J., Porter, A.R. and Krey, G. Effect of dietary conjugated linoleic acid (CLA) on lipid composition, metabolism and gene expression in Atlantic salmon (Salmo salar) tissues. Comparative Biochemistry and Physiology A-Molecular \& Integrative Physiology 145, 258-267 (2006).

Leaver, M.J., Wright, J. and George, S.G. A peroxisomal proliferator-activated receptor gene from the marine flatfish, the plaice (Pleuronectes platessa). Marine Environmental Research 46, 75-79 (1998).

Leonard, A.E., Bobik, E.G., Dorado, J., Kroeger, P.E., Chuang, L.T., Thurmond, J.M., Parker-Barnes, J.M., Das, T., Huang, Y.S. and Mukerji, P. Cloning of a human cdna encoding a novel enzyme involved in the elongation of long-chain polyunsaturated fatty acids. Biochemical Journal 350, 765-770 (2000). 
Leonard, A.E., Kelder, B., Bobik, E.G., Chuang, L.T., Lewis, C.J., Kopchick, J.J., Mukerji, P. and Huang, Y.S. Identification and expression of mammalian long-chain pufa elongation enzymes. Lipids 37, 733-740 (2002).

Leone, T.C., Weinheimer, C.J. and Kelly, D.P. A critical role for the peroxisome proliferator-activated receptor alpha (PPAR ) in the cellular fasting response: the PPAR -null mouse as a model of fatty acid oxidation disorders. Proceedings of the National Academy of Sciences of the United States of America 96, 7473-7478 (1999).

Liang, X.F., Ogata, H.Y. and Oku, H. Effect of dietary fatty acids on lipoprotein lipase gene expression in the liver and visceral adipose tissue of fed and starved red sea bream Pagrus major. Comparative Biochemistry and Physiology A-Molecular and Integrative Physiology 132, 913-919 (2002).

Lindberg, A. and Olivecrona, G. Lipoprotein lipase from rainbow trout differs in several respects from the enzyme in mammals. Gene 292, 213-223 (2002).

Londraville, R.L. and Duvall, C.S. Murine leptin injections increase intracellular fatty acid-binding protein in green sunfish (Lepomis cyanellus). General and Comparative Endocrinology 129, 56-62 (2002).

Londraville, R.L. and Sidell, B.D. Cold acclimation increases fatty acid-binding protein concentration in aerobic muscle of striped bass, Morone saxatilis. Journal of Experimental Zoology 275, 36-44 (1996).

Madsen, L. and Berge, R.K. 3-thia fatty acid treatment, in contrast to eicosapentaenoic acid and starvation, induces gene expression of carnitine palmitoyltransferase II in rat liver. Lipids 34, 447-456 (1999).

Maglich, J.M., Caravella, J.A., Lambert, M.H., Willson, T.M., Moore, J.T. and Ramamurthy, L. The first completed genome sequence from a teleost fish (Fugu rubripes) adds significant diversity to the nuclear receptor superfamily. Nucleic Acids Research 31, 4051-4058 (2003).

Mandard, S., Muller, M. and Kersten, S. Peroxisome proliferator-activated receptor alpha target genes. Cellular and Molecular Life Sciences 61, 393-416 (2004).

Marquardt, A., Stohr, H., White, K. and Weber, B.H.F. cDNA cloning, genomic structure, and chromosomal localization of three members of the human fatty acid desaturase family. Genomics 66, 175-183 (2000).

Mashek, D.G. and Coleman, R.A. Cellular fatty acid uptake: the contribution of metabolism. Current Opinion in Lipidology 17, 274-278 (2006).

Matarese, V., Stone, R.L., Waggoner, D.W. and Bernlohr, D.A. Intracellular fatty-acid trafficking and the role of cytosolic lipid-binding proteins. Progress in Lipid Research 28, 245-272 (1989).

Maxwell, K.N., Soccio, R.E., Duncan, E.M., Schayek, E. and Breslow, J.L. Novel putative SREBP and LXR target genes identified by microarray analysis in liver of cholesterol-fed mice. Journal of Lipid Research 44, 2109-2119 (2003).

Mcpherson, R. and Gauthier, A. Molecular regulation of SREBP function: the INSIGSCAP connection and isoform-specific modulation of lipid synthesis. Biochemistry and Cell Biology-Biochimie Et Biologie Cellulaire 82, 201-211 (2004).

Mead, J.R., Irvine, S.A. and Ramji, D.P. Lipoprotein lipase: structure, function, regulation, and role in disease. Journal of Molecular Medicine-Jmm 80, 753-769 (2002). 
Menoyo, D., Diez, A., Lopez-Bote, C.J., Casado, S., Obach, A. and Bautista, J.M. Dietary fat type affects lipid metabolism in Atlantic salmon (Salmo salar L.) And differentially regulates glucose transporter glut4 expression in muscle. Aquaculture 261, 294-304 (2006).

Menoyo, D., Izquierdo, M.S., Robaina, L., Gines, R., Lopez-Bote, C.J. and Bautista, J.M. Adaptation of lipid metabolism, tissue composition and flesh quality in gilthead sea bream (Sparus aurata) to the replacement of dietary fish oil by linseed and soyabean oils. British Journal of Nutrition 92, 41-52 (2004).

Menoyo, D., Lopez-Bote, C.J., Bautista, J.M. and Obach, A. Growth, digestibility and fatty acid utilization in large Atlantic salmon (Salmo salar) fed varying levels of n-3 and saturated fatty acids. Aquaculture 225, 295-307 (2003).

Menoyo, D., Lopez-Bote, C.J., Obach, A. and Bautista, J.M. Effect of dietary fish oil substitution with linseed oil on the performance, tissue fatty acid profile, metabolism, and oxidative stability of Atlantic salmon. Journal of Animal Science 83, 2853-2862 (2005).

Meyer, A., Kirsch, H., Domergue, F., Abbadi, A., Sperling, P., Bauer, J., Cirpus, P., Zank, T.K., Moreau, H., Roscoe, T.J., Zahringer, U. and Heinz, E. Novel fatty acid elongases and their use for the reconstitution of docosahexaenoic acid biosynthesis. Journal of Lipid Research 45, 1899-1909 (2004).

Meyer, A. and Van De Peer, Y. From 2r to 3r: evidence for a fish-specific genome duplication (FSGD). Bioessays 27, 937-945 (2005).

Michalik, L., Auwerx, J., Berger, J.P., Chatterjee, V.K., Glass, C.K., Gonzalez, F.J., Grimaldi, P.A., Kadowaki, T., Lazar, M.A., O'rahilly, S., Palmer, C.N.A., Plutzky, J., Reddy, J.K., Spiegelman, B.M., Staels, B. and Wahli, W. International union of pharmacology. LXI. Peroxisome proliferator-activated receptors. Pharmacological Reviews 58, 726-741 (2006).

Mommsen, T.P., Silverstein, J.T., Plisetskaya, E.M., Whittaker, L.J., Whittaker, J. and Conlon, J.M. Two insulins from channel catfish: purification, structures, receptorbinding and cDNA sequences. Fish Physiology and Biochemistry 25, 61-70 (2001).

Morais, S., Knoll-Gellida, A., Andre, M., Barthe, C. and Babin, P.J. Conserved expression of alternative splicing variants of peroxisomal acyl- CoA oxidase 1 in vertebrates and developmental and nutritional regulation in fish. Physiological Genomics 28, 239-252 (2007).

Morgan, I.J., Mccarthy, I.D. and Metcalfe, N.B. The influence of life-history strategy on lipid metabolism in overwintering juvenile Atlantic salmon. Journal of Fish Biology 60, 674-686 (2002).

Moya-Falcon, C., Hvattum, E., Tran, T.N., Thomassen, M.S., Skorve, J. and Ruyter, B. Phospholipid molecular species, beta-oxidation, desaturation and elongation of fatty acids in Atlantic salmon hepatocytes: effects of temperature and 3-thia fatty acids. Comparative Biochemistry and Physiology B-Biochemistry \& Molecular Biology 145, 68-80 (2006).

Nanton, D.A., Lall, S.P., Ross, N.W. and Mcniven, M.A. Effect of dietary lipid level on fatty acid beta-oxidation and lipid composition in various tissues of haddock, Melanogrammus aeglefinus L. Comparative Biochemistry and Physiology BBiochemistry \& Molecular Biology 135, 95-108 (2003). 
Nanton, D.A., Vegusdal, A., Benze-Roraa, A.M., Ruyter, B., Baeverfjord, G. and Torstensen, B. Muscle lipid storage pattern, composition and adipocyte distribution in different parts of Atlantic salmon (Salmo salar) fed fish oil and vegetable oil. Aquaculture 265, 230-243 (2007).

Navarro, I., Rojas, P., Capilla, E., Albalat, A., Castillo, J., Montserrat, N., Codina, M. and Gutierrez, J. Insights into insulin and glucagon responses in fish. Fish Physiology and Biochemistry 27, 205-216 (2002).

Nelson, L.E. and Sheridan, M.A. Gastroenteropancreatic hormones and metabolism in fish. General and Comparative Endocrinology 148, 116-124 (2006).

Odom, D.T., Zizlsperger, N., Gordon, D.B., Bell, G.W., Rinaldi, N.J., Murray, H.L., Volkert, T.L., Schreiber, J., Rolfe, P.A., Gifford, D.K., Fraenkel, E., Bell, G.I. and Young, R.A. Control of pancreas and liver gene expression by HNF transcription factors. Science 303, 1378-1381 (2004).

Oku, H., Koizumi, N., Okumura, T., Kobayashi, T. and Umino, T. Molecular characterization of lipoprotein lipase, hepatic lipase and pancreatic lipase genes: effects of fasting and refeeding on their gene expression in red sea bream Pagrus major. Comparative Biochemistry and Physiology B-Biochemistry \& Molecular Biology 145, 168-178 (2006).

Oku, H., Ogata, H.Y. and Liang, X.F. Organization of the lipoprotein lipase gene of red sea bream Pagrus major. Comparative Biochemistry and Physiology B-Biochemistry \& Molecular Biology 131, 775-785 (2002).

Papasani, M.R., Robison, B.D., Hardy, R.W. and Hill, R.A. Early developmental expression of two insulins in zebrafish (Danio rerio). Physiological Genomics 27, 79-85 (2006).

Perez-Sanchez, J., Calduch-Giner, J.A., Mingarro, M., De Celis, S.V.R., Gomez-Requeni, P., Saera-Vila, A., Astola, A. and Valdivia, M.M. Overview of fish growth hormone family. New insights in genomic organization and heterogeneity of growth hormone receptors. Fish Physiology and Biochemistry 27, 243-258 (2002).

Peters, J.M., Lee, S.S.T., Li, W., Ward, J.M., Gavrilova, O., Everett, C., Reitman, M.L., Hudson, L.D. and Gonzalez, F.J. Growth, adipose, brain, and skin alterations resulting from targeted disruption of the mouse peroxisome proliferator-activated receptor ( ). Molecular and Cellular Biology 20,5119-5128 (2000).

Pike, I. Eco-efficiency in aquaculture: global catch of wild fish used in aquaculture. Internatonal Aquafeed 38-40 (2005).

Planas, J.V., Mendez, E., Banos, N., Capilla, E., Navarro, I. and Gutierrez, J. Insulin and IGF-I receptors in trout adipose tissue are physiologically regulated by circulating hormone levels. Journal of Experimental Biology 203, 1153-1159 (2000).

Plisetskaya, E.M. Some of my not so favorite things about insulin and insulin-like growth factors in fish. Comparative Biochemistry and Physiology B-Biochemistry \& Molecular Biology 121, 3-11 (1998).

Plisetskaya, E.M., Ottolenghi, C., Sheridan, M.A., Mommsen, T.P. and Gorbman, A. Metabolic effects of salmon glucagon and glucagon-like peptide in coho and chinook salmon. General and Comparative Endocrinology 73, 205-216 (1989).

Price, N.T., Van Der Leij, F.R., Jackson, V.N., Corstorphine, C.G., Thomson, R., Sorensen, A. and Zammit, V.A. A novel brain-expressed protein related to carnitine palmitoyltransferase I. Genomics 80, 433-442 (2002). 
Regost, C., Arzel, J., Robin, J., Rosenlund, G. and Kaushik, S.J. Total replacement of fish oil by soybean or linseed oil with a return to fish oil in turbot (Psetta maxima) - 1 . Growth performance, flesh fatty acid profile, and lipid metabolism. Aquaculture 217, 465-482 (2003).

Richard, N., Kaushik, S., Larroquet, L., Panserat, S. and Corraze, G. Replacing dietary fish oil by vegetable oils has little effect on lipogenesis, lipid transport and tissue lipid uptake in rainbow trout (Oncorhynchus mykiss). British Journal of Nutrition 96, 299-309 (2006).

Richards, J.G., Bonen, A., Heigenhauser, G.J.F. and Wood, C.M. Palmitate movement across red and white muscle membranes of rainbow trout. American Journal of Physiology-Regulatory Integrative and Comparative Physiology 286, R46-R53 (2004).

Riley, L.G., Fox, B.K., Kaiya, H., Hirano, T. and Grau, E.G. Long-term treatment of ghrelin stimulates feeding, fat deposition, and alters the gh/igf-i axis in the tilapia, Oreochromis mossambicus. General and Comparative Endocrinology 142, 234-240 (2005).

Robinson-Rechavi, M., Marchand, O., Escriva, H., Bardet, P.L., Zelus, D., Hughes, S. and Laudet, V. Euteleost fish genomes are characterized by expansion of gene families. Genome Research 11, 781-788 (2001).

Rollin, X., Medale, F., Gutieres, S., Blanc, D. and Kaushik, S.J. Short- and long-term nutritional modulation of acetyl-coa carboxylase activity in selected tissues of rainbow trout (Oncorhynchus mykiss). British Journal of Nutrition 89, 803-810 (2003).

Rosen, E.D., Sarraf, P., Troy, A.E., Bradwin, G., Moore, K., Milstone, D.S., Spiegelman, B.M. and Mortensen, R.M. PPAR gamma is required for the differentiation of adipose tissue in vivo and in vitro. Molecular Cell 4, 611-617 (1999).

Ruyter, B., Andersen, O., Dehli, A., Farrants, A.K.O., Gjoen, T. and Thomassen, M.S. Peroxisome proliferator activated receptors in Atlantic salmon (Salmo salar): effects on ppar transcription and acyl-CoA oxidase activity in hepatocytes by peroxisome proliferators and fatty acids. Biochimica Et Biophysica Acta-Lipids and Lipid Metabolism 1348, 331-338 (1997).

Saera-Vila, A., Calduch-Giner, J.A., Gomez-Requeni, P., Medale, F., Kaushik, S. and Perez-Sanchez, J. Molecular characterization of gilthead sea bream (Sparus aurata) lipoprotein lipase. Transcriptional regulation by season and nutritional condition in skeletal muscle and fat storage tissues. Comparative Biochemistry and Physiology BBiochemistry \& Molecular Biology 142, 224-232 (2005).

Sargent, J.R. and Tacon, A.G.J. Development of farmed fish: a nutritionally necessary alternative to meat. Proceedings of the Nutrition Society 58, 377-383 (1999).

Sargent, J.R., Tocher, D.R. and Bell, J.G. The lipids. In Fish Nutrition. Third Edition. Ed Halver, J.E. and Hardy, R.W. San Diego, Academic Press 181-257 (2002).

Seiliez, I., Panserat, S., Corraze, G., Kaushik, S. and Bergot, R. Cloning and nutritional regulation of a delta 6-desaturase-like enzyme in the marine teleost gilthead seabream (Sparus aurata). Comparative Biochemistry and Physiology B-Biochemistry \& Molecular Biology 135, 449-460 (2003).

Seiliez, I., Panserat, S., Kaushik, S. and Bergot, P. Cloning, tissue distribution and nutritional regulation of a delta 6-desaturase-like enzyme in rainbow trout. 
Comparative Biochemistry and Physiology B-Biochemistry \& Molecular Biology 130, 83-93 (2001).

Shearer, K.D. and Swanson, P. The effect of whole body lipid on early sexual maturation of 1+age male chinook salmon (Oncorhynchus tshawytscha). Aquaculture 190, 343367 (2000).

Shepherd, B.S., Johnson, J.K., Silverstein, J.T., Parhar, I.S., Vijayan, M.M., Mcguire, A. and Weber, G.M. Endocrine and orexigenic actions of growth honnone secretagogues in rainbow trout (Oncorhynchus mykiss). Comparative Biochemistry and Physiology A-Molecular \& Integrative Physiology 146, 390-399 (2007).

Sheridan, M.A. Regulation of lipid metabolism in poikilothermic vertebrates. Comparative Biochemistry and Physiology B-Biochemistry \& Molecular Biology 107, 495-508 (1994).

Sprecher, H. Metabolism of highly unsaturated n-3 and n-6 fatty acids. Biochimica Et Biophysica Acta-Molecular and Cell Biology of Lipids 1486, 219-231 (2000).

Stubhaug, I., Froyland, L. and Torstensen, B.E. Beta-oxidation capacity of red and white muscle and liver in Atlantic salmon (Salmo salar L.) - Effects of increasing dietary rapeseed oil and olive oil to replace capelin oil. Lipids 40, 39-47 (2005).

Stubhaug, I., Lie, O. and Torstensen, B.E. Beta-oxidation capacity in liver increases during parr-smolt transformation of Atlantic salmon fed vegetable oil and fish oil. Journal of Fish Biology 69, 504-517 (2006).

Stubhaug, I., Lie, O. and Torstensen, B.E. Fatty acid retention and -oxidation capacity in Atlantic salmon tissues (Salmo salar) fed different dietary fish- or vegetable oils: A life cycle study. Aquaculture Nutrition 13, 145-155 (2007).

Tachibana, K., Kobayashi, Y., Tanaka, T., Tagami, M., Sugiyama, A., Katayama, T., Ueda, C., Yamasaki, D., Ishimoto, K., Sumitomo, M., Uchiyama, Y., Kohro, T., Sakai, J., Hamakubo, T., Kodama, T. and Doi, T. Gene expression profilingof potential peroxisome proliferator-activated receptor (PPAR) target genes in human hepatoblastoma cell lines inducibly expressing different PPAR isoforms. Nuclear Receptor 3, 3 (2005).

Tacon, A.G.J. Use of fish meal and fish oil in aquaculture. Aquatic Resources,Culture and Development 1, 3-14 (2004).

Tocher, D.R. Metabolism and functions of lipids and fatty acids in teleost fish. Reviews in Fisheries Science 11, 107-184 (2003).

Tocher, D.R., Leaver, M.J. and Hodgson, P.A. Recent advances in the biochemistry and molecular biology of fatty acyl desaturases. Progress in Lipid Research 37, 73-117 (1998).

Tocher, D.R., Zheng, X.Z., Schlechtriem, C., Hastings, N., Dick, J.R. and Teale, A.J. Highly unsaturated fatty acid synthesis in marine fish: cloning, functional characterization, and nutritional regulation of fatty acyl delta 6 desaturase of Atlantic cod (Gadus morhua L.). Lipids 41, 1003-1016 (2006).

Tontonoz, P., Hu, E., Graves, R.A., Budavari, A.I. and Spiegelman, B.M. mPPAR 2 tissue-specific regulator of an adipocyte enhancer. Genes \& Development 8, 12241234 (1994).

Torstensen, B.E. and Stubhaug, I. Beta-oxidation of $18: 3 \mathrm{n}-3$ in Atlantic salmon (Salmo salar L.) hepatocytes treated with different fatty acids. Lipids 39, 153-160 (2004). 
Tschop, M., Smiley, D.L. and Heiman, M.L. Ghrelin induces adiposity in rodents. Nature 407, 908-913 (2000).

Van Der Leij, F.R., Huijkman, N.C.A., Boomsma, C., Kuipers, J.R.G. and Bartelds, B. Genomics of the human carnitine acyltransferase genes. Molecular Genetics and Metabolism 71, 139-153 (2000) .

Veerkamp, J.H. and Vanmoerkerk, H.T.B. Fatty-acid-binding protein and its relation to fatty-acid oxidation. Molecular and Cellular Biochemistry 123, 101-106 (1993).

Volkoff, H., Eykelbosh, A.J. and Peter, R.E. Role of leptin in the control of feeding of goldfish Carassius auratus: interactions with cholecystokinin, neuropeptide Y and orexin A, and modulation by fasting. Brain Research 972, 90-109 (2003).

Wendelaar Bonga, S.E. The stress response in fish. Physiological Reviews 77, 591-625 (1997).

Willumsen, N., Vaagenes, H., Lie, O., Rustan, A.C. and Berge, R.K. Eicosapentaenoic acid, but not docosahexaenoic acid, increases mitochondrial fatty acid oxidation and upregulates 2,4-dienoyl-CoA reductase gene expression in rats. Lipids 31, 579-592 (1996).

Wisely, G.B., Miller, A.B., Davis, R.G., Thornquest, A.D., Johnson, R., Spitzer, T., Sefler, A., Shearer, B., Moore, J.T., Miller, A.B., Willson, T.M. and Williams, S.P. Hepatocyte nuclear factor 4 is a transcription factor that constitutively binds fatty acids. Structure 10, 1225-1234 (2002).

Woods, I.G., Wilson, C., Friedlander, B., Chang, P., Reyes, D.K., Nix, R., Kelly, P.D., Chu, F., Postlethwait, J.H. and Talbot, W.S. The zebrafish gene map defines ancestral vertebrate chromosomes. Genome Research 15, 1307-1314 (2005).

Yeung, C.M., Chan, C.B., Woo, N.Y.S. and Cheng, C.H.K. Seabream ghrelin: cDNA cloning, genomic organization and promoter studies. Journal of Endocrinology 189, 365-379 (2006) .

Zhang, Y.Y., Proenca, R., Maffei, M., Barone, M., Leopold, L. and Friedman, J.M. Positional cloning of the mouse obese gene and its human homolog. Nature 372, 425-432 (1994).

Zheng, X., Seiliez, I., Hastings, N., Tocher, D.R., Panserat, S., Dickson, C.A., Bergot, P. and Teale, A. Characterization and comparison of fatty acyl delta 6 desaturase cDNAs from freshwater and marine teleost fish species. Comparative Biochemistry and Physiology B-Biochemistry \& Molecular Biology 139, 269-279 (2004a).

Zheng, X.Z., Tocher, D.R., Dickson, C.A., Bell, J.G. and Teale, A.J. Effects of diets containing vegetable oil on expression of genes involved in highly unsaturated fatty acid biosynthesis in liver of Atlantic salmon (Salmo salar). Aquaculture 236, 467483 (2004b).

Zheng, X.Z., Tocher, D.R., Dickson, C.A., Bell, J.G. and Teale, A.J. Highly unsaturated fatty acid synthesis in vertebrates: new insights with the cloning and characterization of a delta 6 desaturase of Atlantic salmon. Lipids 40, 13-24 (2005a).

Zheng, X.Z., Torstensen, B.E., Tocher, D.R., Dick, J.R., Henderson, R.J. and Bell, J.G. Environmental and dietary influences on highly unsaturated fatty acid biosynthesis and expression of fatty acyl desaturase and elongase genes in liver of Atlantic salmon (Salmo salar). Biochimica Et Biophysica Acta-Molecular and Cell Biology of Lipids 1734, 13-24 (2005b). 
Zhou, S.Y., Ackman, R.G. and Morrison, C. Storage of lipids in the myosepta of Atlantic salmon (Salmo salar). Fish Physiology and Biochemistry 14, 171-178 (1995). 